\title{
Abstracts of the First European Conference on "Biofilms - prevention of microbial adhesion", held at the Deutsche Bundesstiftung Umwelt DBU in Osnabrück, Germany, from 31 March to 2 April 2004
}

PAPER ABSTRACTS

Centre for Biomedical Microbiology, Biocentrum, Technical University of Denmark and OSI-Pharma A/S, Building 301, 2800 Kgs Lyngby, Denmark

\author{
Jamming the command language of bacteria: \\ a new approach to the control of bacterial \\ infections
}

\section{Givskov}

Control of growth of unwanted bacteria is one of the most important technical achievements of humankind. In medicine and agriculture, treatment scenarios are based on antibacterial compounds, such as antibiotics, with toxic and growth inhibitory properties. Opportunistic pathogens often cause persistent (chronic) infections that can lead to tissue dysfunction and inflammation. One important aspect is that opportunist pathogens live as biofilm communities in the host. Biofilms are ubiquitous in nature and more than $60 \%$ of all microbial infections are now believed to involve biofilms. In this state the bacteria tolerate the highest deliverable doses of antibiotics, which makes them impossible to eradicate. Biofilm infections are becoming more and more common owing to the widespread use of medical implants (catheters, artificial heart valves, etc.). Such surfaces create ideal environments for the development of biofilm infections. Taking patient age distribution and medical advances into account, this will become a major medical problem of the twenty-first century; one that requires urgent attention. The solution may lie in the design of a new generation of target-specific, antipathogenic (as opposed to antibacterial) drugs.

Several bacteria are capable of working together and show organized behavior when they establish themselves and express their arsenal of tissuedamaging virulence factors in a eukaryotic host. To facilitate this, the bacteria have developed a primitive, chemically based, command language termed quorum sensing (QS). QS enables bacteria to keep track of their numbers and is considered to play a role in minimizing host responses: the production of virulence factors is delayed until sufficient bacteria have been amassed to overwhelm the host defence mechanisms and strategically cause disease. But QS is also a way by which bacteria expose part of their genetic repertoire towards other organisms, prokaryotes as well as eukaryotes. The central role of QS systems in expression of host-associated phenotypes, including virulence factor production and biofilm development, and the fact that they function by means of external low molecular weight signals make them ideal drug targets. Compounds able to paralyse the command language do not affect any vital function of the bacterium and thus will not interfere with its growth. When growth is not affected, there is no selection pressure for the development of resistant bacteria and they are not expected to eliminate communities of helpful and beneficial bacteria present in the host. 
Department of Microbiology, Institute of Plant Biology, University of Zürich, Zollikerstrasse 107, CH-8008 Zürich, Switzerland

E leberl@botinst.unizh.ch
In my presentation, I outline a strategy for the isolation and identification of new antipathogenic drugs and deliver a proof of concept. I also demonstrate that such antipathogenic compounds are present in certain foods and suggest that diet may offer a natural prophylaxis and treatment against chronic infections.

\section{The cep quorum-sensing system of Burkholderia cepacia H111 plays a pivotal role for biofilm formation and pathogenicity}

\section{Eberl}

Burkholderia cepacia and Pseudomonas aeruginosa often co-exist as mixed biofilms in the lungs of patients suffering from cystic fibrosis. The isolation of 13 random mini-Tn5 insertion mutants of $B$. cepacia $\mathrm{H} 111$ that are defective in biofilm formation on a polystyrene surface is reported. We show that the screening procedure used in this study is biased towards mutants defective in the late stages of biofilm development. A detailed quantitative analysis of the biofilm structures formed by the wild type and mutant strains revealed that the isolated mutants are impaired in their abilities to develop a typical threedimensional biofilm structure. Molecular investigations showed that the genes required for biofilm maturation fall into several classes: (1) genes encoding surface proteins, (2) genes involved in the biogenesis and maintenance of an integral outer membrane, and (3) genes encoding regulatory factors. It is shown that three of the regulatory mutants produce greatly reduced amounts of $\mathrm{N}$-octanoylhomoserine lactone (C8-HSL). This compound serves as the major signal molecule of the cep quorum-sensing system, which consists of the acylated homoserine lactone (AHL) synthase CepI and the cognate C8-HSL receptor protein CepR. By using a Caenorhabditis elegans pathogenesis model, it is shown that the cep system of H111 is required for efficient killing of the nematode. Hence, quorum sensing in B. cepacia links surface colonization with pathogenicity.

\section{Detachment of Shewanella oneidensis MR1 biofilms}

\section{A. M. Spormann*, K. Thormann, R. Saville and S. Shukla}

Shewanella oneidensis MR1 is a facultative Fe- and Mn-reducing microorganism that has become a model system for studying microbe-mineral interactions. The organism is capable of forming biofilms, thereby leading to direct metabolic interactions between layers of biofilm cells and mineral surfaces. This may result in direct mineral dissolution or corrosion, creating eminent implications with regard to biogeochemical processes. Our group is therefore developing a basic understanding of the stages of biofilm formation and microbe-mineral interactions. Studies using $g f p$-labeled wild-type and mutant cells in conjunction with confocal laser scanning microscopy revealed key steps and stages of the biofilm formation of S. oneidensis MR1. 
* Corresponding author: C. Matz

E c.matz@unsw.edu.au

School of Biotechnology and Biomolecular Sciences, Centre for Marine Biofouling and Bio-Innovation, University of New South Wales, Sydney 2052, Australia
* Corresponding author: O. Wanner

E Oskar.Wanner@eawag.ch

1 Swiss Federal Institute for Environmental Science and Technology (EAWAG), CH-8600 Dübendorf, Switzerland

2 Swiss Federal Laboratories for Materials Testing and Research (EMPA), CH-8600 Dübendorf and $\mathrm{CH}-9014$ St Gallen, Switzerland
A very critical, yet poorly understood, step in the dynamics and propagation of biofilms is the detachment of single or aggregated cells. We discovered that S. oneidensis cells detached rapidly from hydrodynamically grown biofilms when the medium flow was turned off, leading to a loss of biomass of up to $80 \%$ after $15 \mathrm{~min}$. Further experiments to elucidate the responsible signal(s) showed that the most important trigger inducing this detachment is oxygen depletion, whereas carbon starvation does not seem to be involved. Furthermore, the observed detachment is not dependent on cellular motility. Knockout mutations in genes encoding known and potential regulators responsible for the response to oxygen starvation, etrA, $\operatorname{arc} A$ and $\operatorname{crp}$, were constructed and the mutants tested for their detachment behavior. The results revealed that disruption of $\operatorname{arcA}$ or crp leads to pronounced defects in flow-induced detachment, while etrA appears to play rather a minor role in this phenomenon.

Our experiments show that biofilms of S. oneidensis MR1 are capable of quickly responding to changes in levels of molecular oxygen and give insight into how the dispersal of biofilms might be induced and regulated.

\section{Protozoan grazing on biofilms and the role of quorum sensing in grazing resistance}

\section{Matz*, T. Bergfeld, S. A. Rice and S. Kjelleberg}

To understand biofilm growth and control in natural and artificial systems it is crucial to study ecological factors that commonly limit bacterial survival. Protozoan grazing is a major mortality factor for bacterial populations. We studied the survival mechanisms of Pseudomonas aeruginosa biofilms in response to protozoan grazing. Early biofilms showed the formation of grazing-resistant microcolonies in the presence of the flagellate grazers, while biofilms without the predator were undifferentiated. Our results suggest a role of quorum sensing in early biofilms and the involvement of flagella, type IV pili and alginate in the formation of grazing-resistant microcolonies. More mature biofilms exhibited acute toxicity to the flagellate grazer. Rapid growth of the flagellate on quorum-sensing mutants indicated a key role of quorum sensing in the upregulation of lethal factors in late biofilms. We suggest that the central role of quorum-sensing-regulated grazing resistance provides a potential target in the bio-control of surface-associated bacteria.

\section{Control of heat exchanger biofilms}

\section{O. Wanner ${ }^{1 *}$, V. Panagiotidis', P. Delavy ${ }^{1,2}$, R. Hany², T. Geiger ${ }^{2}$ and M. Zinn ${ }^{2}$}

Waste water contains large amounts of energy. This energy can be recovered by a heat pump in combination with a heat exchanger installed in the sewer system. However, in the nutrient-rich waste water, biofilms form rapidly on the heat exchanger and significantly reduce its efficiency. Various parameters and measures that could affect the adhesion and formation of biofilms were studied on a small heat exchanger installed in a pilot-scale waste-water channel. Various finishes of the heat exchanger surface were tested. It was found that there is an optimal roughness of the steel surface. Various industrial coatings 


\footnotetext{
* Corresponding author: K. Riedel

E riedel@quorum-sensing.de

1 Department of Microbiology, Technical University of Munich, Am Hochanger 4, D-85350 Freising, Germany

2 4SC AG, Am Klopferspitz 19a, D-82152 Martinsried, Germany

3 Department of Microbiology, Institute of Plant Biology, University of Zürich, Zollikerstrasse 107, CH-8008 Zürich, Switzerland
}

with antifouling properties were tested. As an alternative coating, a bacterially produced polyhydroxyalkanoate was used, after it was covalently linked with the natural antifouling compound zosteric acid and structural analogues. For some coatings the results were positive; however, at present the significance of the improvement remains unclear. Disturbance of the flow field with small obstacles mounted on the heat exchanger surface was effective, but the effect was difficult to assess quantitatively. The most effective measure turned out to be the systematic change of hydraulic force. This measure worked always and repeatedly and, on average, increased the efficiency of the heat exchanger with biofilm from $60 \%$ to $83 \%$ relative to the efficiency of the clean heat exchanger.

\section{Computer-aided design of a novel antibacterial agent for the treatment of Burkholderia cepacia infections}

\section{K. Riedel ${ }^{1 *}$, M. Köthe', B. Kramer' ${ }^{2}$, W. Saeb ${ }^{2}$, A. Gotschlich ${ }^{2}$, A. Ammendola ${ }^{2}$ and L. Eberl ${ }^{1,3}$}

Burkholderia cepacia is an opportunistic pathogen that can cause severe pulmonary deterioration in patients with cystic fibrosis. Efficient treatment of $B$. cepacia infections is often hampered by the intrinsic resistance of the organism to a large range of antibiotics. We report on the computer-aided design of a novel agent that specifically targets the quorum-sensing (QS) system of $B$. cepacia $\mathrm{H} 111$, which is a central regulator for the expression of pathogenic traits. The novel agent was demonstrated to interfere with several known QSregulated functions in B. cepacia $\mathrm{H} 111$; expression of extracellular proteolytic activity and AidA, swarming motility and biofilm formation were strongly inhibited in the presence of the compound and were virtually indistinguishable from the acylated homoserine lactone (AHL)-negative mutant H111-I. Target validation by proteomics indicated that the compound specifically inhibits the cep regulatory system of $B$. cepacia. Most importantly, in the presence of this agent the virulence of B. cepacia was attenuated in a Caenorhabditis elegans pathogenesis model. The novel anti-infective drug has great potential as a therapeutic option for treating B. cepacia infections, which, owing to the intrinsic resistance of the organism, are extremely difficult, if not impossible, to eradicate.

\section{Anaerobic regulatory network essential for efficient Pseudomonas aeruginosa biofilm formation}

\section{Schobert ${ }^{1 *}$, M. Hentzer ${ }^{2}$, K. Schreiber ${ }^{1}$, N. Quaeck ${ }^{1}$, M. Givskov' ${ }^{2}$, L. Jaensch ${ }^{3}$ and D. Jahn'}

Pseudomonas aeruginosa is the dominant pathogen causing chronic respiratory infections and is the leading cause of mortality in cystic fibrosis patients. Direct microscopic observations of lung tissue samples revealed that 
* Corresponding author: M. Frant

E marion.frant@iba-heiligenstadt.de

Institute for Bioprocessing and Analytical Measurement Techniques, Rosenhof 37308, Heilbad Heiligenstadt, Germany
P. aeruginosa forms biofilm-like macrocolonies. Recent data showed that cystic fibrosis airway mucus is anaerobic and contains low amounts of nitrate, which allows anaerobic energy generation via denitrification. Therefore $P$. aeruginosa infection of the cystic fibrosis lung requires biofilm formation and persistence in an anaerobic environment. Only limited information is available about the anaerobic metabolism in $P$. aeruginosa biofilms. Three regulatory systems are required for anaerobic growth in the presence of nitrate: Anr, detecting oxygen; Dnr, measuring nitric oxide; and NarXL, the two-component system that detects nitrate. We studied the influence of these regulators on anaerobic biofilm formation, structure and metabolism. Recent results of the investigation of the regulatory network underlying anaerobic biofilm growth and survival are presented.

\section{Development and testing of a new phosphorylcholine polymer coating to prevent biofilm formation on optical fiber sensor systems}

\section{K. Liefeith, M. Frant ${ }^{\star}$ and G. Hildebrand}

Monitoring of medical and biotechnological processes is becoming more critical for industry. The aim of this study was to demonstrate the feasibility of using biocompatible antifouling coatings based on phosphorylcholine (PC) on optical sensing materials. On the basis of existing technology two PC-polymer coatings were developed and tested on glass surfaces.

Of fundamental importance was the investigation of specific interactions that influence adhesion mechanisms of cells and biofilm formation. Investigations were focused therefore on the physicochemical characterization of the surfaces. On the basis of these studies the determination of adhesion kinetics of human blood cells and proteins (fibrinogen, albumin) and marine organisms was performed. Adhesion processes were simulated by means of special bioreactor systems that were connected to a flow-through chamber system for online adhesion measurements.

It was found that the PC-polymer-coated glass surface was more bioinert and haemocompatible. The physicochemical characterization studies showed a significant difference between the uncoated and PC-coated surfaces.

In conclusion the coupling of biotechnological tools and specific flow chambers with surface-sensitive test methods proved to be useful for investigating new materials under reproducible conditions. Thus the PC-coated surfaces showed a clear antifouling behaviour under dynamic test conditions.

\section{Bactericidal layers based on silver nanoparticles}

\section{H. Schmidt}

A new production and coating technology for efficient antimicrobial layers was developed. For the first time these systems contain a microbicidal component as well as an antiadhesive component. Silver nanoparticles were chosen as the bactericidal agent. These particles were prepared from molecular precursors combined with a surface modification agent either by a photolytic or a thermal nucleation and growth step. The process allowed control of both the size and the number of particles. During examination of the release behaviour of silver ions 
* Corresponding author: J. Eck

E je@brain-biotech.de

1 B.R.A.I.N Aktiengesellschaft, Darmstädterstrasse 34, 64673 Zwingenberg, Germany

2 Zentrum für molekulare Evolution und Biodiversität (ZEB e.V.) am Institut für Mikrobiologie und Genetik, TU-Darmstadt, Schnittspahnstrasse 10, 64287 Darmstadt, Germany

3 Max-Planck-Institut für Entwicklungsbiologie, Spemannstrasse 35, 72076

Tübingen, Germany from the layer it was shown that, after an initial period, the amount of released silver is almost constant. A gradient layer was used for the assessment of the antiadhesive properties. The formation of the gradient occurs during drying of the lacquer. Oligomers of perfluorinated organosilanes diffused to the surface and became concentrated there. The fluorinated chains were oriented to the outside and contact angles against water of more than $100^{\circ}$ and against hexadecane of more than $70^{\circ}$ were obtained. Thus the surface possessed hydrophobic as well as oleophobic properties. These properties made it difficult for microorganisms to adhere to the surface. First commercial possibilities are use in the coating of in-the-canal hearing aids and the development of a production line to coat pharmaceutical containers.

\section{Metagenomics: a novel tool to exploit microbial communities for industrial applications}

\section{G. Meurer ${ }^{1}$, R. Schulze ${ }^{1}$, P. Lorenz ${ }^{1}$, A. Treusch ${ }^{2}$, S. Schuster ${ }^{3}$, C. Schleper ${ }^{2}$ and J. Eck ${ }^{1 *}$}

Accessing the genetic blueprints of entire microbial consortia, the so-called "metagenomes", provides insight into functionally meaningful molecular sequences for industrial application. The entire microbial biodiversity is a powerful resource for the development of novel drugs, enzymes and bioactive compounds. However, biotechnology has failed to screen $99 \%$ of existing microbial resources because of an inability to cultivate most microorganisms from microbial communities. Novel strategies of directly cloning "metagenome DNA" to obtain the genetic blueprints of entire microbial consortia are becoming increasingly applicable to circumvent this problem $[1,2,3]$.

Here we report on the evaluation and expression of high molecular weight DNA from a metagenome cloned as Large-Insert Libraries (LIL ${ }^{\circledR} s$ ), as well as the development of flexible LIL $^{\circledR}$ expression systems for heterologous expression of metagenome DNA in biosynthetically competent expression hosts. The biosynthetic potential captured in our libraries was examined by screening three fosmid LIL $^{\circledR}$ s of diverse habitats, comprising a total of 2.5 Gbp metagenome DNA (Gbp is gigabase-pairs), for the production of novel enzymes as well as novel antimicrobial activities and the presence of secondarymetabolite-producing biosynthetic gene clusters. Metagenome clones displaying antibacterial activities against chloramphenicol-resistant Bacillus subtilis or Staphylococcus aureus indicator strains in overlay screening assays were identified, sequenced and subjected to further investigation. Sequencehomology-based screening methods revealed novel sequences obtained by polymerase chain reaction (PCR) typing methods, using degenerate PCR primers to target functional domains in type I polyketide synthase (PKS) and non-ribosomal peptide synthetase (NRPS) gene clusters.

\section{REFERENCES}

1. Lorenz, P., Liebeton, K., Niehaus, F. \& Eck, J. (2002) Current Opinion in Biotechnology 13, 572-577

2. Quaiser, A., Ochsenreiter, T., Klenk, H.-P., Kletzin, A., Treusch, A., Meurer, G., et al. (2002) Envirionmental Microbiology 4, 603-611

3. Lorenz, P., Liebeton, K., Niehaus, F., Schleper, C. \& Eck, J. (2003) Biocatalysis and Biotransformation 21, 87-91 
Hochschule Magdeburg-Stendal (FH), Postfach 3655, 39011 Magdeburg,

Germany

E harald.horn@chemie.hsmagdeburg.de

\section{Formation of biofilms - do not forget the hydrodynamics}

\section{H. Horn}

In all kinds of reactors and distribution systems the hydrodynamic conditions are a main parameter influencing and sometimes promoting the growth of microorganisms on, and adhesion of microorganisms to, surfaces. Biofilm growth, structure, density and thickness are influenced mainly by the hydrodynamic conditions and substrate supply. Low flow velocities and high substrate supply (i.e. high growth rates) lead to less-dense biofilms. On the other hand, high flow velocities and low substrate supply (i.e. low growth rates) can lead to both compact biofilm structures and the formation of streamers.

Detachment from biofilms in technical systems is caused by a combination of processes including abrasion, erosion, sloughing and predator grazing. Detachment occurs when external forces (e.g. through shear) are larger than the internal strength of the matrix that is holding the biofilm together and on the surface. Thus there are two mechanisms that can lead to detachment:

(1) increase of the external shear forces by increase of the flow velocity, and

(2) decrease of the internal strength (e.g. through hydrolysis of the polymeric biofilm matrix).

Formation and detachment of biofilms belong together. They are investigated with methods such as confocal laser scanning microscopy (CLSM) and/or magnetic resonance imaging (MRI). Mathematical models were used to describe the formation and detachment of biofilms with respect to the hydrodynamic conditions in the biofilm system. The models used focused on substrate conversion, mass transfer and transport. Furthermore, the distribution of bacteria and the extracellular polymeric substances (EPS) in the biofilm and the detachment due to shear stress caused by an increase in flow velocity were simulated. The simulation was done mainly to increase the understanding of biofilm formation.

\section{Microbial adhesion - a target for the development of household and industrial products}

\section{R. Breves*, D. Bockmühl, M. Heinzel and M. Weide}

The adhesion of microbes is an important feature in the evaluation of products with antimicrobial effects. Examples are coatings for hard surfaces in industry and domestic use, laundry hygiene and oral care products. Besides bacteria, pathogenic fungi such as Candida albicans are an important target organism: C. albicans causes mucosal infections such as candidiasis, diaper dermatitis and vaginal candidosis.

A more complex approach is followed by the concept of molecular triggers. These molecules interfere with the genetic regulation of the morphological state of the dimorphic yeast C. albicans. Trigger molecules that shift C. albicans into the yeast state prevent adhesion to fabrics. Product formulations in full-scale washing trials showed a significant reduction of C. albicans after the wash and prevented cross-contamination to formerly uncontaminated clothes. 
Ahlstrom Osnabrück $\mathrm{GmbH}$, Römereschstrasse 33, Osnabrück 49090, Germany
* Corresponding author: A. Lipski

E Andre.Lipski@Biologie.Uni-

Osnabrueck.de

\section{Concept of a specialty paper producer to avoid microbiological problems}

\section{Reiter}

This paper discusses general aspects of microbiological control in the paper industry, using the paper mill Ahlstrom Osnabrück $\mathrm{GmbH}$ as an example of a treatment concept. Today there is no generally valid procedure for handling microbiological problems in a paper mill. Even two paper machines at one site operating under different production programs can necessitate different treatments. An overview of the current treatment concepts of different biocide suppliers is given.

Paper mills provided excellent growth conditions for some microorganisms. The effect of uncontrolled growth and the goals for a rational treatment regimen are described.

The microbiologically affected areas are highlighted and the treatment concept of Ahlstrom Osnabrück is presented. Some of the measurement methods are described. Improvements can be reached through a better treatment concept using different chemicals such as oxidizing agents or considering other areas of potential dosage such as the freshwater system. A good example of close cooperation between a supplier of raw materials and a biocide supplier is described.

The limits of the treatment with biocides and the need for developing alternative methods are discussed.

\section{Identification of primary biofilm organisms on steel surfaces of bottling plants}

\section{Winkler, M. Timke, K. Altendorf and A. Lipski}

An extensive approach for the characterization of biofilms asociated with brewery bottling plant revealed a high microbial diversity. This high diversity suggests a large degree of flexibility in the ability of these communities to respond successfully to cleaning and disinfecting procedures. However, in contrast to the developed biofilm with a high potential of diverse resistance mechanisms, we expected that, during the primary colonization phase, only a few microorganisms are involved. During this phase, resistance to disinfecting procedures should be minimal. Therefore we started an approach for the identification and characterization of the primary colonizers of a brewery bottling plant surface.

Sterile and cleaned steel coupons were placed on selected sites at the bottling plant. The coupons were exposed overnight. Half the coupons were removed the next morning before the first cleaning procedure started and half of the coupons passed through this cleaning procedure and were then removed before the bottling process started. One set of these coupons was subjected to a fixation procedure for subsequent fluorescence in situ hybridization (FISH) analysis and stored at $4{ }^{\circ} \mathrm{C}$. A second set were stained with 4',6-diamidino-2'-phenylindoledihydrochloride (DAPI) for quantification of attached cells by fluorescence microscopy. Those coupons removed before the cleaning procedure showed up to 170 cells $/ \mathrm{mm}^{2}$, while coupons removed after this cleaning procedure showed cell densities up to 40 cells $/ \mathrm{mm}^{2}$.

Microorganisms from the coupons were isolated by stamping the coupons on R2A-plates. Out of 100 isolates, 70 were chosen for detailed characterization. 
The 70 isolates were differentiated into 14 groups on the basis of their fatty acid profiles. Representative strains from each group were subjected to Gram-stain, $\mathrm{KOH}$ and oxidase test, a microscopic characterization of the cell morphology and partial $16 \mathrm{~S}$ rDNA sequencing. On the basis of these methods and in accord with the fatty acid data, the isolates were assigned to the genera Bacillus, Deinococcus, Acinetobacter, Janthinobacterium, Enterobacter, Pseudomonas, Sphingomonas, Aeromonas and Chryseobacterium. Specific rRNA-directed oligonucleotide probes were selected and tested for hybridization with representative isolates from each group. These probes were used for the identification of the dominating primary colonizers on the fixed steel coupons. Only probe GAM42a, specific for most Gammaproteobacteria gave significant signals, with up to $40 \%$ positive cells related to total cell numbers on the basis of DAPI staining.

Representative strains of all groups were characterized for their attachment to glass and polystyrene surfaces. Attachment to glass surfaces was tested by exposure of microscopic slides for $1 \mathrm{~h}$ in liquid cultures of the test strains. After incubation, the density of attached cells at the slide versus concentration of suspended cells in the medium was calculated. Attachment to polystyrene was tested in microtitre plates. After growth in the microtitre plates, suspended cells were discarded and the attached cells were stained with crystal violet. The biofilm-retained stain was dissolved with ethanol and quantified photometrically. With both tests, a strain identified as Acinetobacter showed intense biofilm formation. This is in accord with the high detection rate of Gammaproteobacteria on the exposed steel coupons.

Further studies are aimed to verify the occurrence of Acinetobacter cells on exposed steel coupons by more specific oligonucleotide probes and the in-depth characterization of the attachment mechanisms of these strains by reflection electron microscopy (REM) and atomic force microscopy (AFM) analyses for micromorphological studies, detection of EPS by fluorescence staining and resistence of attached cells to several disinfectants.

* Corresponding author: W.-R. Abraham E wab@gbf.de

GBF, Mascheroder Weg 1, 38124 Braunschweig, Germany

\section{Carbon sharing in complex microbial biofilms grown on polychlorinated biphenyl droplets}

\section{S. Tillmann, K. N. Timmis and W.-R. Abraham*}

Polychlorinated biphenyls (PCB) are hydrophobic environmental toxins. To find bacterial communities actively mineralizing these toxins, droplets of PCB were exposed to soil samples polluted with 13500 p.p.m. (parts per million) PCB. A complex biofilm community developed within a few weeks. Some isolates from the biofilms were able to grow on monochlorinated PCB congeners, whereas the PCB biofilm community degraded tri- and tetrachlorinated congeners as well. To identify the organisms responsible for their degradation ${ }^{13} \mathrm{C}$-labelled congeners were added to the PCB droplets and the incorporation of ${ }^{13} \mathrm{C}$ into the fatty acids of the lipids was monitored. We found good ${ }^{13} \mathrm{C}$ incorporation in some fatty acids, while others were not labelled at all. The fatty acids labelled by ${ }^{13} \mathrm{C}$ incorporation from a dichlorinated congener were the same as those found in the Burkholderia isolates, demonstrating that Burkholderia species are the degraders of this congener. Using stable isotope tracers, it could be shown that the multi-species biofilm is able to degrade compounds that are not attacked by its isolated members, pointing to a complex system of substrate sharing and metabolic networks in the biofilm. 


\footnotetext{
* Corresponding author: F. Beier

E BeierF@salzgitter-ag.com

1 Salzgitter Flachstahl $\mathrm{GmbH}$, Salzgitter AG, Eisenhüttenstrasse 99, 38239 Salzgitter, Germany

2 Department of River Ecology, UFZ Centre for Environmental Research, Brueckstrasse 3a, D-39114 Magdeburg, Germany

3 Hydrochemistry, Hochschule Magdeburg-Stendal (FH), Postfach 3655, 39011 Magdeburg, Germany
}

* Corresponding author: M. Kästner

E Matthias.kaestner@ufz.de

1 Department of Groundwater Microbiology, Centre for Environmental Research UFZ Leipzig-Halle, D-04318 Leipzig, Germany

2 Department of Bioremediation, Centre for Environmental Research UFZ Leipzig-Halle, D-04318 Leipzig Germany

3 University of Tennessee, Center for Biomarker Analysis, Knoxville, TN 37932, USA

4 Institut für Agrarökologie, Bundesforschungsanstalt für Landwirtschaft, D-38116, Braunschweig, Germany
Development of methods for assessing microbial colonization of coil-coated steel sheets

\author{
F. Beier ${ }^{1 *}$, T. R. Neu ${ }^{2}$, C. Staudt ${ }^{2}$, A. Seelmann ${ }^{3}$ \\ and H. Horn ${ }^{3}$
}

Due to an increasing demand for non-toxic, antimicrobial surfaces on prepainted steel, paint manufactures and coil-coaters are looking for methods to assess the performance of various coating materials. As current knowledge of microbial colonization of common coil-coating paints is very limited, laboratory methods to investigate microbial fouling have to be extrapolated to workplace conditions. Therefore the growth of omnipresent microorganisms was studied on standard and antimicrobial-containing paint coverings. In addition, zinc-coated sheets and copper sheets were studied as a reference. The steel slides with different coatings were exposed to river water and/or humid air in rotating annular reactors for 4 weeks. Biofilm development was investigated using confocal laser scanning microscopy (CLSM). Bacteria were stained with SYTO 60 and the extracellular polymeric substance (EPS) glycoconjugates were stained with fluorescent-labelled lectins. Algae were detected by their autofluorescence. Although the slides were cleaned weekly with isopropanol (70\%), microorganisms could be detected on the surfaces shortly after the cleaning procedure. No significant difference could be found between the applied coatings. The aim of these studies was to increase our understanding of the conditions that will permit or inhibit microbial growth. This information is expected to promote the development of coil coatings with tailor-made properties.

\section{Microbial in situ activity assessment using "BACTRAPS" with ${ }^{13} \mathrm{C}$-labelled substrates}

\section{R. Geyer ${ }^{1}$, N. Stelzer ${ }^{2}$, D. C. White ${ }^{3}$, E. Rakhimova ${ }^{4}$, C. Tebbe ${ }^{4}$, H.-H. Richnow ${ }^{2}$ and M. Kästner ${ }^{2 *}$}

The anaerobic aquifer of a former hydrogenation plant in Zeitz (Saxony, Germany) contaminated with benzene and toluene has shown significant biodegradation of toluene by isotope fractionation analysis. Indications were also found of the anaerobic biodegradation of benzene within the aquifer. Clear evidence for biodegradation of benzene and its use as a carbon source by microorganisms was still lacking. Unique 'BACTRAPS' containing Bio-Sep ${ }^{\circledR}$ beads, loaded with ${ }^{13} \mathrm{C}$-labelled benzene and toluene under sterile conditions, were used to enrich biofilms within groundwater-monitoring wells. The beads facilitate the enrichment of microorganisms through entrapment and biofilm formation via consumption of the labelled substrates. Lipid biomarkers and DNA were extracted from the beads after 5 weeks' exposure and were analysed with mass spectrometry and molecular biological methods. Of the loaded substrate, $80 \%$ was degraded and isotopic analysis of fatty acids clearly verified benzene and toluene degradation with concomitant formation of biomass. Total lipid fatty acids and polar lipid fatty acids (PLFAs), isotopic composition, and polymerase chain reaction/single-strand conformation polymorphism (PCR/SSCP) patterns showed differences between the two compounds that can be used to follow the path of the labelled carbon within the developing microbial community. 
* Correponding author: B. Manz

E Bertram.Manz@ibmt.fraunhofer.de

1 Fraunhofer-Institut fü Biomedizinische Technik, Ensheimer Strasse 48, 66386 St Ingbert, Germany

2 Hydrochemistry, Hochschule Magdeburg-Stendal (FH), 39114 Magdeburg, Germany
* Corresponding author: B. Zippel

E barbara.zippel@ufz.de

Department of River Ecology, UFZ Centre for Environmental Research Leipzig-Halle, Brueckstrasse 3A, 39114 Magdeburg, Germany

\section{Magnetic resonance imaging as a tool for non-invasive imaging of biofilms}

\section{B. Manz ${ }^{1 *}$, F. Volke ${ }^{1}$, D. Goll ${ }^{2}$ and H. Horn ${ }^{2}$}

The understanding of biofilm formation and growth requires accurate and non-invasive methods for measuring structure and transport properties. In this contribution it is shown that non-invasive magnetic resonance imaging (MRI) techniques can be employed to study these properties in biofilm systems.

The investigations were carried out for defined heterotrophic biofilms that were cultivated in a tube reactor. So-called relaxation time maps were used to produce MR contrast and to spatially resolve the biofilm structure. Structural parameters, such as biofilm thickness, surface enlargement and roughness are presented for different biofilms. Furthermore, flow behaviour near the biofilm/bulk water interface and particularly in the hydrodynamic boundary layer was studied by imaging the local flow velocities. Results showed that the local shear stress at the surface of the investigated biofilms can be up to three times higher as compared with the mean shear stress calculated from the mean flow velocity in the reactor.

The formation of biofilms is not only a question of the substratum with respect to hydrophobic and/or lipophilic conditions but is also strongly coupled to the hydrodynamic conditions in the bulk phase. Therefore the MRI technique is the only available method that combines the measurement of biofilm structure and hydrodynamic conditions.

\section{Phototrophic biofilms - development and growth characteristics in a special flow chamber}

\section{B. Zippel ${ }^{\star}$ and T. R. Neu}

Phototrophic biofilms may be defined as interfacial microbial communities driven mainly by light as the energy source. Photosynthetic microorganisms generate energy and reduce carbon dioxide, providing organic substances and oxygen that fuel processes and conversions in the heterotrophic biofilm community. Adhesion, development and functioning of freshwater phototrophic biofilms were investigated, with the following aims: (1) optimization of waste-water bioremediation, (2) control and prevention of biofouling on submerged objects, and (3) modelling of phototrophic biofilm development. Experiments were carried out in a special flow lane incubator with precise control of external light, temperature and velocity conditions. Adapted light sensors measured the attenuation of subsurface light below the polycarbonate substratum during phototrophic biofilm growth. Artificial medium with inocula-adapted nutrient concentrations was exchanged twice each week to avoid nutrient limitation. The structure and architecture of phototrophic biofilms were analysed at different stages of development (initial settlement/adhesion; active growth, aged/matured stage) by using laser scanning microscopy. The distribution of eukaryotic and prokaryotic microorganisms within the biofilm was detected according to their autofluorescence and after nucleic acid staining. Glycoconjugate distribution was determined by using lectin binding analysis. 
E schrempf@biologie. uni-osnabrueck.de

Universität Osnabrück, Fachbereich Biologie/Chemie, Barbarastrasse 11, 49069 Osnabrück, Germany

\section{A new mechanism of bacterial adhesion to materials and organisms containing the chitin and/or chitosan}

\section{H. Schrempf}

Chitin is the second most abundant (gigatonnes per year) renewable polysaccharide in nature and consists of unbranched chains of linked $N$-acetylglucosamine residues which may associate in a parallel $(\beta)$ or antiparallel $(\alpha)$ fashion. $\beta$-Chitin is abundant as an exoskeleton and/or peritrophic membrane in many organisms as well as a cell-wall component within many fungi, including pathogenic ones. Fungi can also contain chitosan. Within marine chitin-containing organisms, the $\beta$-type is abundant and chitosan can also be found. Within chitin-containing organisms chitin is synthesized by chitin synthetases and chitosan is derived by enzymatic deacetylation of chitin. Members of a new family of bacterial secreted proteins (CHBs) of about $18-19 \mathrm{kDa}$ have been identified; they lack enzymatic activity but specifically target materials or organisms containing $\alpha$ - and/or $\beta$-chitin and/or chitosan $[1,2,5]$.

Proteins of this family targeting $\beta$-chitin ( $\mathrm{CHB} 1$ and $\mathrm{CHB} 2)$ or different chitin types and chitosan (CHB3) were initially found within various Streptomyces species [2,5] and then were identified (ChbB) within Bacillus amyloliquefaciens strains [6]. On the basis of these findings, homologues of CHBs could be found in Serratia marcescens as well as in Pseudomonas aeruginosa strains $[8,9]$. The solution structure of monomeric CHB1 (the model type for $\mathrm{CHBs}$ ) was deduced by X-ray solution scattering, revealing the presence of two domains [4]. The specificity of binding to $\alpha$-chitin is very high $\left(K_{d} 0.11 \mu \mathrm{M}\right)$. High levels of chaotropic agents or reduction of the two disulphide bonds in CHB1 abolish adhesion to the polysaccharide. Using designed mutant proteins and biochemical studies, the presence of certain tryptophan and cysteine residues within CHB1 were identified as being required for specific binding to isolated $\alpha$-chitin or to $\beta$-chitin within organisms (e.g. crab, insects, worms, fungi). The studied CHBs were also found to build aggregates that form a glue-like structure around chitin-containing organisms and to invade chitin fibres. In the course of biofilm formation with chitin-containing organisms and materials, streptomycetes secrete a repertoire of enzymes (e.g. chitinases and others). The breakdown products are taken up via specific transport systems [7].

Inspection of genomic sequences of many bacteria, including pathogenic ones, reveals that many of them have a homologue of CHBs. The implications in biofilm formation are discussed.

\section{REFERENCES}

1. Zeltins, A. \& Schrempf, H. (1997) European Journal of Biochemistry 246, 557-564

2. Kolbe, S., Fischer, S., Becirevic, A., Hinz, P. \& Schrempf, H. (1998) Microbiology 144, 1291-1297

3. Kristufek, V., Fischer, S., Bührmann, J., Zeltins, A. \& Schrempf, H. (1999) FEMS Microbiology and Ecology 28, 41-48

4. Svergun, D. I., Becirevic, A., Schrempf, H., Koch, M. H. J. \& Grüber, G. (2000) Biochemistry 39, 10677-10683

5. Saito, A., Miyashita, K., Biukovick, G. \& Schrempf, H. (2001) Applied Environmental Microbiology 67, 1268-1273

6. Chu, H. H., Hoang, V., Hofemeister, J. \& Schrempf, H. (2001) Microbiology 147, 1793-1803

7. Xiao, X., Wang, F., Saito, A., Majka, J., Schlösser, A. \& Schrempf, H. (2002) Molecular and General Genetics 267, 429-439 
* Corresponding author:

H.-C. Flemming

E hh239wi@uni-duisburg.de

University of Duisburg-Essen, Institute of Interface Biotechnology, Geibelstrasse 41, D-47057 Duisburg, Germany
* Corresponding author: S. Wuertz

E swuertz@ucdavis.edu

1 Water and Steam Chemistry Laboratory; BARC Facilities, Kalpakkam, Tamil Nadu 603 102, India

2 Institute of Water Quality and Waste Management; Technical University of Munich, Am Coulombwall, D-85748 Garching, Germany

3 Department of Civil and Environmental Engineering, University of California, Davis, One Shields Avenue, Davis, CA 95616, USA
8. Suzuki, K., Suzuki, M., Taiyoji, M., Nikaidou, N. \& Watanabe T. (1998) Bioscience Biotechnology and Biochemistry 62, 128-135

9. Folders, J., Tommassen, J., van Loon, L. C. \& Bitter, W. (2000) Journal of Bacteriology $182,1257-1263$

\section{Extracellular polymeric substances - the "glue" of biofilms}

\section{H.-C. Flemming ${ }^{\star}$ and J. Wingender}

Extracellular polymeric substances (EPS) are biopolymers of microbial origin, located outside the cells. They surround biofilm cells and, in biofilms, they form a three-dimensional highly hydrated matrix, enabling adhesion of biofilms to their support and cohesion of the matrix. Their composition varies widely, according to species diversity, nutrient composition and availability, and hydrodynamic conditions. In general, they consist of polysaccharides; proteins, glycoproteins, glycolipids, phospholipids and nucleic acids have been reported also. EPS can be involved in the first steps of microbial adhesion to solid surfaces, or they are secreted only after cell attachment. They maintain the integrity of biofilms and determine the biofilm architecture. They fill and form the space between the cells and have a profound influence on their immediate environment. Intermolecular forces are involved in the functional structure of the matrix, for example by binding extracellular enzymes and preventing their loss to the surrounding medium. Cohesion is mediated by weak physico-chemical interactions such as hydrogen bonds as well as electrostatic interactions, van der Waals interactions and hydrophobic interactions. In the case of the exopolysaccharide alginate of Pseudomonas aeruginosa, detailed investigations revealed that not only does the core polymer, consisting of mannuronate and guluronate residues, play a role in the cohesive forces but substituents such as acetyl groups further influence the mechanical properties of the EPS matrix and hence the three-dimensional biofilm architecture. The concentration and species of cations, for example calcium, are also relevant to the mechanical stability of the matrix owing to bridging of polyanions. EPS contribute to the protection of biofilms from antimicrobial agents, either directly by neutralization of these substances or indirectly by forming the biofilm environment within which microbial populations inherently adopt biocide-resistant phenotypes. As a consequence, EPS biosynthesis, secretion and network formation can be considered as potential targets for the prevention, killing and removal of biofilms.

\section{Sphingomonas biofilm architecture grown under different hydrodynamic conditions}

\section{P. Venugopalan', M. Kuehn' ${ }^{2}$, M. Hausner ${ }^{2}$ and S. Wuertz ${ }^{3 *}$}

The architecture of a bacterial biofilm was studied during the early phases of its formation, using strain L138, a $g f p$-tagged derivative of Sphingomonas sp. strain L126, as a model organism, and flow cells and confocal laser scanning microscopy as experimental tools. Biofilm biomass and extracellular polymeric substances (EPS) distribution in space and time, development of microcolonies under flow conditions representing Reynolds numbers of 0.07, 52 and 87, and 
* Corresponding author: T. Birkenstock

E timo.birkenstock@uni-tuebingen.de

1 Microbial Genetics, University of Tübingen, Auf der Morgenstelle, 28 D-72076 Tübingen, Germany

2 Division of Infectious Diseases, University Hospital Basel, Hebelstrasse 20, 4031 Basel, Switzerland changes in diffusion length with reference to EPS production were studied by sequential sacrificing of biofilms grown in multi-channel flow cells and by time-lapse confocal imaging. Comparability of biofilms growing in different channels of the flow cell, as well as the minimum area of biofilm to be imaged to get a representative area were established initially. The area of biofilm in terms of microscopic images required to ensure representative sampling varied by an order of magnitude when areal cell coverage $\left(2 \times 10^{5} \mu \mathrm{m}^{2}\right)$ or microcolony size $\left(1 \times 10^{6} \mu \mathrm{m}^{2}\right)$ was the biofilm parameter under investigation. Hence it is necessary to establish the inherent variability of any biofilm parameter one is attempting to quantify.

Sphingomonas sp. L138 biofilm architecture consisted of microcolonies and extensive water channels. Analysis of the confocal stacks showed that biomass and EPS distribution in the biofilm were maximal at $8-9 \mu \mathrm{m}$ above the substratum. Consequently, the higher void fraction near the substratum may allow environmental fluids greater access to the biofilm base. Initial periods of biofilm formation $(0-8 \mathrm{~h}$ ) were characterized by dynamic fluctuations in biovolume, indicating growth/accretion and/or dislodgement of cells. Timelapse confocal imaging and digital image analysis showed that growth of the microcolonies was not uniform, adjacent colonies registered significant growth or no growth at all. Another significant observation was that microcolonies had the ability to move across the attachment surface as a unit, irrespective of fluid flow direction. Results suggest that movement of microcolonies is an inherent property of the biofilm. The width of voids (water channels) decreased as EPS production increased, resulting in increased diffusion distances in the biofilm. Changing the hydrodynamic conditions had no discernable influence on the characteristics of microcolonies (size, shape, orientation with respect to flow) during the first $24 \mathrm{~h}$ of biofilm development. In conclusion, experimental evidence indicates the overriding effects of inherent factors, visà-vis environmental factors, on the early stages of microcolony development under the given experimental conditions.

\section{Molecular basis of biofilm formation in staphylococci and its implication for virulence}

\section{F. Götz ${ }^{1 *}$, T. Birkenstock' , S. Cramton', S. Kristian ${ }^{1,2}$ and R. Landmann ${ }^{2}$}

The genetic and molecular basis of biofilm formation in staphylococci is multifaceted. The ability to form a biofilm requires at least two properties: the adherence of cells to a surface and accumulation to form multi-layered cell clusters. A trademark is the production of the slime substance polysaccharide intercellular adhesin (PIA), a polysaccharide composed of $\beta$-1,6-linked $\mathrm{N}$-acetylglucosamines with partly deacetylated residues, in which the cells are embedded and protected against the host's immune defense and antibiotic treatment. Mutations in the corresponding biosynthesis genes (ica operon) lead to a pleiotropic phenotype; the cells are biofilm- and hemagglutinationnegative, and less adhesive to hydrophilic surfaces. There is evidence that IcaB acts as a deacetylase that removes the acetyl residues of the $\beta$-1,6-linked $\mathrm{N}$-acetylglucosamine polymer. The partly deacetylated and completely acetylated PIA exhibit clear biochemical characteristics. Some biofilm-negative mutants have been isolated in which PIA production appeared to be unaffected. Two of the characterized mutants are affected in the major autolysin $(a t l E)$ and in D-alanine esterification of teichoic acids (dltA). Wild-type Staphylococcus aureus SA113 and its ica-negative mutant were compared with respect to host cell response and in various animal models. 
* Corresponding author: T. R. Neu

E neu@gm.ufz.de

1 Department of River Ecology, UFZ Centre for Environmental Research Leipzig-Halle, Brueckstrasse 3A, 39114 Magdeburg, Germany

2 National Water Research Institute, 11 Innovation Boulevard, Saskatoon, Saskatchewan, Canada S7N 3H5
* Corresponding author: C. Heilmann

E heilmac@uni-muenster.de

\section{Extracellular polymeric substances - the dark matter of biofilms}

\section{T. R. Neu ${ }^{1 *}$ and J. R. Lawrence ${ }^{2}$}

Biofilm communities are highly structured associations of cellular and polymeric components that are involved in biogenic and geogenic processes. The interfacial microbial communities in a specific habitat are highly dynamic and change according to the environmental parameters affecting the cellular and polymeric constituents of the biofilm system. For a long time the polymer matrix in biofilms has been neglected. This polymer matrix, consisting of numerous different extracellular polymeric substances (EPS) produced by various organisms, is responsible for many biofilm properties. The EPS interact with the substratum, with cellular constituents as well as with dissolved and suspended components. Owing to the importance of EPS, different approaches have been applied to study them, such as chemical analyses and in situ detection. Laser scanning microscopy in combination with lectin binding analysis has been suggested as an in situ tool to study the glycoconjugate fraction of EPS. Using this approach the "empty" space between cellular biofilm constituents can be investigated. Recent studies have shown that this space is highly organized in terms of structure and function. Thus EPS is a structural as well as a multi-functional component involved in many biofilm processes such as prevention and control, which suggests new directions for investigation.

\section{The multi-functional Staphylococcus aureus autolysin Aaa mediates adherence to immobilized fibrinogen and fibronectin}

\section{Heilmann*, J. Hartleib, M. S. Hussain and G. Peters}

Staphylococci can cause a wide spectrum of infections including endocarditis, osteomyelitis and sepsis, which is reflected in the numerous virulence factors they produce, among them a new class of adhesins - the multifunctional autolysin/adhesins. We recently identified a novel autolysin/adhesin, designated Aaa, from Staphylococcus aureus. The gene encoding Aaa was cloned from the clinical isolate S. aureus 4074. DNA sequence analysis revealed that aaa encodes a deduced protein of 334 amino acid residues, with a predicted molecular mass of $35.8 \mathrm{kDa}$. Aaa contains three repetitive sequences in its $\mathrm{N}$-terminal portion. These repeats comprise features of a putative peptidoglycan-binding domain, the LysM domain. The LysM domain is found in a number of enzymes involved in cell-wall metabolism and is also part of some adhesins, such as the $S$. aureus protein A and elastinbinding protein EbpS. Expression of aaa by Escherichia coli and subsequent characterization revealed that Aaa possesses bacteriolytic activity as well as adhesive properties such as binding to extracellular matrix proteins. Real-time biomolecular interaction analysis demonstrated that the interaction of Aaa with fibrinogen, fibronectin and vitronectin is dose dependent and saturable and occurs with high affinity. Aaa binds to the $A \alpha$ - and $B \beta$-chains of fragment $\mathrm{D}$ of fibrinogen. Immunofluorescence microscopy demonstrated that Aaa is located at the cell surface. Finally, an aaa knockout mutant showed reduced 
* Corresponding author: J. K.-M. Knobloch

E knobloch@uke.uni-hamburg.de adherence to surface-adsorbed fibrinogen and fibronectin, strongly suggesting a role in colonization of host factor-coated polymer surfaces and/or host tissue. Knowledge of the factors involved will help in development of strategies to prevent $S$. aureus biofilm formation on host factor-coated polymer surfaces and host tissue.

\section{Hierarchy within the regulatory cascade of Staphylococcus epidermidis biofilm formation}

\section{J. K.-M. Knobloch*, S. Jäger, M. A. Horstkotte, H. Rohde and D. Mack}

Cell adhesion within Staphylococcus epidermidis biofilms is mediated by polysaccharide intercellular adhesin (PIA), which is synthesized by the gene products of $i c a A D B C$. By transcriptional analysis, we investigated the regulatory network of $i c a A D B C$ transcription, which includes $i c a R, \sigma^{\mathrm{B}}$ and the gene locus yabJ/spoVG. In a biofilm-negative $\sigma^{\mathrm{B}}$ mutant, biofilm formation could be restored by ethanol stress. Transcriptional analysis of $i c a R$ revealed that this negative regulator of $i c a A D B C$ transcription is repressed by $\sigma^{\mathrm{B}}$ activity. Owing to lack of $\sigma^{\mathrm{B}}$ promoter preceding $i c a R$ or $i c a A D B C$ this regulation must be mediated by an as-yet unknown $\sigma^{\mathrm{B}}$-dependent regulatory intermediate. Ethanol stress repressed the $i c a R$ transcription in a $\sigma^{\mathrm{B}}$-independent manner. The positive regulatory gene locus $y a b J / s p o V G$ is preceded by a $\sigma^{\mathrm{B}}$ promoter and transcription is downregulated in the $\sigma^{\mathrm{B}}$ mutant. A Tn 917 mutant lacking yabJ/spoVG transcription was biofilm negative, despite still-repressed icaR transcription. To summarize these data, biofilm formation in S. epidermidis seems to be subject to dual regulation by different ways of repression of the negative regulator $i c a R$. However, this regulation is subordinated to the $\sigma^{\mathrm{B}}$ dependent yabJ/spoVG locus.

\section{Human biofilms in situ}

\section{A. Moter*, R. Lux, M. Berning, D. Kovacevic, C. Mallmann, A. Friedmann, J. Wecke and U. B. Göbel}

Most information on biofilm formation has been derived from in vitro systems showing adhesion, coaggregation and communication between bacteria. However, biofilms of the human body are difficult to mimic, since highly complex and specific components such as body fluids, cell surfaces and the immune system are involved.

Allowing simultaneous visualization, identification, enumeration and localization of individual microbial cells, fluorescence in situ hybridization (FISH) is useful for analysis of biofilm architecture. Since FISH detects not only culturable microorganisms but also fastidious and yet-to-be-cultured bacteria, it is a useful tool for the analysis of complex microbial communities. We used the technique to study in vivo grown human biofilms, for example subgingival plaque in periodontitis or infective endocarditis. FISH showed the high numbers and spatial distribution of not-yet cultured oral spirochaetes and oral pathogens directly within subgingival biofilms of periodontitis patients. 
* Corresponding author: R. Schade

E roland.schade@iba-heiligenstadt.de

Institute for Bioprocessing and Analytical Measurement Techniques, Department of Biomaterials, Rosenhof, 37308 Heiligenstadt, Germany
Furthermore numerous streptococci and staphylococci were visualized in infected heart valves in culture-negative cases.

This approach enables an in vivo check of the in vitro systems and therefore may further our understanding of biofilm development.

\section{An in vitro testing system based on bioreactor technology for the analysis of biofilm formation on dental materials}

\section{R. Schade* and K. Liefeith}

The formation of dental biofilms on prosthetic materials depends on surface characteristics including topographic and energetic material parameters and organic conditioning layers. The initial adhesion processes of dental bacteria crucially determine the formation of dental plaque layers under normal oral hygiene conditions. We developed an in vitro testing system based on a chemostat model to quantify initial bacterial adhesion under relevant working conditions. The system allows the application of defined-flow shear stresses using coupled-flow chambers. We showed a substantial effect of surface topographic and energetic parameters on the adhesion of dental bacteria after a short-term experiment. The results of biofilm formation on different dental biomaterials were confirmed by comparative clinical tests.

The data show that the in vitro system is suitable for testing the effects of surface characteristics. Therefore it is favoured for the validation of strategies to minimize/prevent biofilm formation by surface modifications and antifouling agents.

POSTER ABSTRACTS
Vreden Research Institute of

Traumatology and Orthopedics,

8 Boikova Street, St Petersburg, Russia

\section{Immune compounds - inhibitors of microbial adhesion in cell culture}

\section{A. Afinogenova and G. Afinogenov}

Our aim was to make a comparative evaluation of the antiadhesive activity of normal human immunoglobulin (INH) (Russia), pentaglobin and intraglobin (Biotest, Germany). Tests were made on human skin fibroblasts with clinical isolates of Staphylococcus aureus. The intensity of bacterial adhesion and antiadhesive properties of compounds used were expressed as the following indices: (1) index of adhesion (IA) calculated as the mean number of attached microbes per eukaryotic cell; (2) percentage of affected cells of the monolayer (AC\%); (3) microbial contamination of the monolayer obtained as IA $\times \mathrm{AC} \%$; and (4) percentage of bacterial adhesion inhibition with respect to the control. The control S. aureus IA was $24.1 \pm 3.3, \mathrm{AC} \% 90$; in the presence of INH, IA was $2.1 \pm 0.8, \mathrm{AC} \% 21$; in the presence of intraglobin, IA was $2.0 \pm 0.3, \mathrm{AC} \%$ 20 ; in the presence of pentaglobin, IA was $1.9 \pm 0.2, \mathrm{AC} \% 11$. The protective effect of INH and intraglobin disappeared with the addition of protein A from staphylococcal wall cells to nutrient medium but remained the same for 
1 Department of Microbiology, Technical University of Munich, Am Hochanger 4, D-85350 Freising, Germany

2 Department of Chemical-Technical Analysis and Chemical Food Technology, Technical University of Munich, Weihenstephaner Steig 23, D-85350 Freising, Germany

3 Proteomics Department, Technical University of Munich, Am Forum 2, D-85350 Freising, Germany

4 Department of Microbiology, Institute of Plant Biology, University of Zürich, Zollikerstrasse 107, CH-8008 Zürich, Switzerland
Microbial Genetics, University of Tübingen, Auf der Morgenstelle, 28 D-72076 Tübingen, Germany pentaglobin. In the presence of protein A, IgM makes the anti-adhesive activity of pentaglobin irreversible; these indices show parameters of microbial biofilm formation.

\title{
A proteomic approach to identify quorum-sensing regulated and surface-induced proteins of the rhizobacterium Pseudomonas putida IsoF
}

\author{
C. Arevalo-Ferro', G. Reil ${ }^{2}$, A. Görg ${ }^{3}$, L. Eberl', \\ K. H. Schleifer ${ }^{1}$ and K. Riedel ${ }^{4}$
}

The rhizobacterium Pseudomonas putida exhibits a high plant growthpromoting potential owing to phytostimulation, biocontrol capacity and bioremediation. The traits involved in the rhizosphere competence are still poorly understood. Factors that contribute to the rhizosphere fitness include the capacity of the cells to form biofilms and cell-cell communication systems that enable the bacteria to coordinate the expression of special phenotypes in a cell-density dependent manner. Recently the $p p u$ quorum-sensing (QS) locus of the tomato rhizosphere isolate $P$. putida IsoF was characterized and a QS-deficient ppuI mutant $P$. putida F117 was generated. The goal of this study was to identify surface-induced genes of $P$. putida IsoF that are in addition regulated by QS. For this purpose the intracellular and surface subproteomes of planktonically and biofilm-grown $P$. putida IsoF wild type and its QS-deficient mutant were analysed by two-dimensional polyacrylamide gel electrophoresis. Biofilms were grown in silicon tubes with a controlled LB medium flow. Several proteins that were exclusively expressed in the biofilm mode of growth seem to be QS regulated. Work currently under way aims at the identification of these proteins by mass spectrometry.

\section{Evidence that IcaB deacetylases the staphylococcal $\mathrm{N}$-acetylglucosamine polymer polysaccharide intercellular adhesin}

\section{T. A. Birkenstock, O. Schweitzer and F. Götz}

Previous studies have identified the $\beta$-1,6-linked $N$-acetylglucosamine polymer PIA (polysaccharide intercellular adhesin) as the major component of the extracellular slimy matrix in staphylococcal biofilms. Structural analyses of PIA have shown that it is partially deacetylated. A corresponding deacetylase, however, has not yet been identified. Here, we address the question of whether IcaB plays a role in the deacetylation of PIA. PIA was extracted and purified from Staphylococcus epidermidis O-47, S. epidermidis O-47 icaB::ermB and S. epidermidis O-47 icaB::ermB (pTXicaB). The degree of deacetylation of the respective polysaccharides was compared. Polysaccharides extracted from S. epidermidis O-47 icaB::ermB and from uninduced S. epidermidis O-47 icaB::ermB (pTXicaB) were completely acetylated, while about $15 \%$ of the $\mathrm{N}$-acetylglucosamine residues of PIA purified from S. epidermidis O-47 were deacetylated. Overexpression of icaB in S. epidermidis O-47 icaB::ermB 
* Corresponding author: M. Bössmann

E m.boessmann@tu-bs.de

1 Institute of Biochemical Engineering, Technical University of Braunschweig, Gaussstrasse 17, 38106 Braunschweig, Germany

2 Department of River Ecology, UFZ Centre for Environmental Research Leipzig-Halle, Brueckstrasse 3A, 39114 Magdeburg, Germany

3 Hydrochemistry, Hochschule Magdeburg-Stendal (FH), Breitscheidstrasse 2, 39114 Magdeburg, Germany
* For correspondence:

E dresden@gmbu.de

GMBU e.V., Arbeitsgruppe Funktionelle Schichten, PF 520165, D-01317 Dresden, Germany
(pTXicaB) led to an increase in deacetylation of the $N$-acetylglucosamine polymer. These results strongly indicate that IcaB plays a crucial role in PIA deacetylation.

\section{Microelectrode and confocal laser scanning microscopy study of particle-supported biofilms}

\author{
M. Bössmann ${ }^{1 *}$, C. Staudt ${ }^{1,2}$, T. R. Neu ${ }^{2}$, H. Horn ${ }^{3}$ \\ and D. C. Hempel ${ }^{1}$
}

Particle-supported autotrophic biofilms were cultivated in external-loop airlift reactors at different pumice concentrations. The volume fractions of bacteria and extracellular polymeric substances (lectin-specific extracellular polymeric substances (EPS) glycoconjugates) were measured in living, fully hydrated biofilms. Owing to limited laser penetration, thick biofilms were embedded and cryosectioned in order to investigate the biofilm structure from the biofilm surface through several hundred micrometres down to the substratum. In addition, oxygen microelectrodes were used to investigate substrate transport and conversion rates under defined hydrodynamic conditions in a specially developed flow cell. A low carrier concentration resulted in lessdense biofilms with a heterogeneous surface and lower volume fractions of bacteria and EPS glycoconjugates. They also had a thicker concentration boundary layer and less-steep oxygen concentration profiles as compared with dense biofilms from reactors with high carrier concentrations. Both the microelectrode and confocal laser scanning microscope measurements showed the influence of shear stress on particle-supported biofilms. In conclusion, the combination of both techniques allowed a detailed and quantitative characterization of particle-associated biofilm structure and function.

\section{Biocidal silica coatings}

\section{H. Böttcher, D. Fiedler, B. Mahltig and A. Thron}

Coatings from silica nanosols modified by alkyl and fluoroalkyl silanes show very low surface energies (down to $10 \mathrm{mN} / \mathrm{m}$ ) that can change the growth modes and adhesion of biofilms but not avoid long-term settlement on material surfaces [1]. The embedding of biocidal agents within modified silica layers offers new and interesting possibilities for biocidal coatings. It is possible to encapsulate a broad spectrum of well-known biocides and control their release by the composition and structure of the composite layers. A special advantage is the possibilty of combining different biocides to increase the biocidal effectiveness against different micoorganisms and to diminish the risk of certain microorganisms developing resistance; for example, silica nanosol coatings with embedded colloidal silver or silver compounds combined with organic biocidal compounds decrease very efficiently the survival rate of adherent bacteria for catheters and other medical equipment. Moreover, such modified silica coatings could be shown to yield antimicrobial protection to wood and textiles. 
* Corresponding author: J. Azeredo

E jazeredo@deb.uminho.pt

1 University of Minho, Portugal

2 Harvard University, Cambridge, Massachusetts, USA
* Corresponding author: E.-M. Decker

School of Dental Medicine, University of Tübingen, Germany

\section{REFERENCE}

1. Schmidt, W., Sawusch, S., Breuel, U., Garske, B., Petzoldt, H., Hambsch, B., et al. (2002) Vom Wasser 98, 177-192

\section{Inhibition of adherence of coagulase-negative staphylococci to acrylic by subinhibitory concentrations of antibiotics}

\section{N. Cerca ${ }^{1}$, G. Pier ${ }^{2}$, R. Oliveira ${ }^{1}$ and J. Azeredo ${ }^{1 *}$}

Coagulase-negative staphylococci (CoNS) are major nosocomial pathogens associated with infections of indwelling medical devices. The major virulence factor of these organisms is their ability to adhere to devices and form biofilms. Antibiotics interacting with the cell wall may influence bacterial adhesion by causing changes in the cell surface. These cell surface modifications may increase or decrease bacterial adherence to biomaterials. In this study we determined the effect of sub-MIC (minimum inhibitory concentration) concentrations of cefazolin, vancomycin and dicloxacillin on the adhesion of several CoNS clinical isolates to an acrylic surface. The results showed a minimal effect for vancomycin on reducing adhesion, although this antibiotic had a very low MIC value, and thus a high efficiency in killing bacteria in suspension. Cefazolin and dicloxacillin induced a higher inhibition of adhesion, reaching more than $60 \%$ for some strains, although these antibiotics have a lower efficiency of killing bacteria in suspension. Combinations of the drugs were evaluated and a synergistic effect was observed. Use of antibiotics that inhibit adherence of CoNS to biomaterials may augment other treatment strategies for device-related infections.

\section{The influence of antiplaque agents on streptococcal biofilm grown on enamel and glass}

\section{E.-M. Decker*, R. Weiger, C. von Ohle, I. Wiech and $M$. Brecx}

Three antiplaque agents (chlorhexidine, CHX-0.1\%; chitosan, Chit- $0.2 \%$; octenisept, Oct- $0.1 \%$ ) and saline (NaCl- $0.9 \%$, negative control) were used for the treatment ( $2 \mathrm{~min}$ ) of the early cariogenic colonizer Streptococcus sanguinis in a pre-clinical biofilm model $(n=10)$. The pre-treated streptococci were allowed to attach to human enamel or glass (favoured for its transparency). The aim of the study was to compare the biofilm features (vitality and cell density) after treatment with the test agents.

1. The mean values ( $95 \%$ confidence intervals) for bacterial vitality (\%) were:

\begin{tabular}{lc}
\hline Enamel & Glass \\
\hline NaCl: $70.23(58.54-81.93)$ & $67.68(58.93-76.43)$ \\
CHX: $14.30(6.05-22.55)$ & $23.63(14.52-32.74)$ \\
Chit: $71.25(62.28-80.22)$ & $61.11(53.89-68.84)$ \\
Oct: $0.05(0.14-1.96)$ & $4.35(2.24-6.46)$ \\
\hline
\end{tabular}


2. The mean values (95\% confidence intervals) for bacterial cell numbers (log colony forming units) were:

\begin{tabular}{ll}
\hline Enamel & Glass \\
\hline $\mathrm{NaCl}: 3.53(3.27-3.78)$ & $3.69(3.34-4.04)$ \\
$\mathrm{CHX}: 2.60(3.33-2.88)$ & $2.61(2.38-2.83)$ \\
Chit: $2.51(2.37-2.64)$ & $2.09(1.99-2.18)$ \\
Oct: $2.33(1.982 .49)$ & $1.74(1.50-1.97)$ \\
\hline
\end{tabular}

The application of the antiplaque agents showed some significant differences with regard to the cell density on enamel as compared with glass.

* Corresponding author: C. Staudt

E staudt@gm.ufz.de

1 Department of River Ecology, UFZ Centre for Environmental Research Leipzig-Halle, Brueckstrasse 3A, 39114 Magdeburg, Germany

2 Department of Computing Science, Otto-von-Guericke-University, Universitätsplatz 2, 39106 Magdeburg, Germany

3 National Water Research Institute, 11 Innovation Boulevard, Saskatoon, Saskatchewan, Canada, S7N 3H5

Geomicrobiology, ICBM, Carl von Ossietzky University Oldenburg, PO Box 2503, 26111 Oldenburg, Germany

\section{Comparison of digital image analysis programs for confocal laser scanning microscopy data sets of biofilms}

\section{A. Eitner ${ }^{1}$, C. Staudt ${ }^{1 *}$, O. Buettner ${ }^{1}$, S. Bergner ${ }^{2}$, K. Tönnies ${ }^{2}$, J. R. Lawrence ${ }^{3}$ and T. R. Neu ${ }^{1}$}

Laser scanning microscopy of biofilms may be used for three reasons: visualization, analysis and quantification. The last two, however, remain problematical as environmental microbial biofilms show a complex composition and the software packages available have a number of limitations. The image files used for analysis were three-channel images showing nucleic-acidstained bacteria, lectin-stained glycoconjugates, chlorophyll autofluorescence as well as co-localization of cyanobacterial autofluorescence. In order to analyse multi-channel data of lotic biofilms, four software packages each with specific individual features were compared. These included: NIH Image/Scion Image/ImageJ (freely available), Comstat (freely available), Voxelshop (commercial) and Microstat (tailor made). With all programs, the most important and critical step in digital image analysis is the segmentation procedure. In conclusion, the sample properties and the purpose of the analysis as well as the financial budget will finally determine the decision to select a specific program for digital image analysis of laser scanning microscopy data sets.

\section{Fungal biofilms on mineral materials}

\section{A. A. Gorbushina, W. E. Krumbein and M. Volkmann}

Scientific approaches to the safeguarding of building materials such as façade stone, roof tiles and insulation systems and especially of cultural heritage buildings have evolved over the years to a high level of sophistication. The analysis and the treatment of detrimental biofilms have made progress in many directions. One of the factors is the awareness not only of biologically initiated chemical but also physical and mechanical damage functions. Rock surface colonization is an important starting point in the development of all terrestrial ecosystems. Complex microbial communities inhabit the 


\footnotetext{
* Corresponding author: R. Oliveira

E roliveira@deb.uminho.pt

University of Minho, Portugal
}

interface between rock substrate and the atmosphere. Chemoorganotrophic microorganisms (fungi and bacteria), phototrophic green algae, cyanobacteria and lichens are essential constituents of subaerial biofilms. Subaerial rock communities metabolize under extremely limited water availability and high sun irradiation levels and can be found even on desert rocks and at high altitudes. Subaerial epi- and endolithic biofilms create and maintain biologically modified environments where mineral solubility and dissolution rates are significantly altered. Fungi are the most persistent inhabitants of the subaerial rock biofilms due to their hyphal and/or yeast-like growth mode and the remarkable stress tolerance of certain ecological groups. However, in complex subaerial biofilms free-living fungi frequently maintain mutually beneficial contacts with bacteria and phototrophic organisms. Fungal influence on solid rocks is manifested through (1) a mechanical impact on grain cohesion through turgor pressure, (2) a series of excreted secondary metabolic products (low molecular weight organic acids and organic polymers including diverse pigments and antioxidants) and (3) biologically induced formation of new minerals (carbonates, oxalates, oxides, phosphates and silicates or silica). The geomicrobiological and biogeochemical role of fungal metabolic products on rock surfaces are discussed. Special attention is given to the individual protective pigments and survival enhancing metabolic products. Another line of evolution of techniques and application proposals is the application of biocidal chemicals. Detrimental effects of poikilophilic algal, cyanobacterial and especially fungal films and networks are numerous. In our work natural products rather than industrially synthesized chemicals are combined with new biological and physical techniques to make biofilms vulnerable to chemicals and thus able to kill the associated microorganisms before they adhere firmly and establish themselves as detrimental biofilms.

\section{The influence of subinhibitory concentrations of fluconazol and amphotericin $B$ in the adhesion of different Candida species to acrylic}

\section{Henriques, J. Azeredo and R. Oliveira*}

The most common antifungal agents used to treat candidiasis are fluconazol and amphotericin B. Adhesion of candidal species is the first step in oral pathogenesis, therefore it is very important to study the behaviour of the adhesion of yeasts submitted to subinhibitory concentrations of antifungal agents. In this study adhesion involved Candida albicans and Candida dubliniensis. In order to simulate real conditions the adhesion assays were performed using a medium with artificial saliva and acrylic as substratum, the latter being the material used to produce prosthetic devices. The results showed that, in the case of $C$. albicans, the adherence decreased in the presence of fluconazol ( $1 / 4$ minimum inhibitory concentration $(\mathrm{MIC})=0.25 \mu \mathrm{g} / \mathrm{ml})$. In the case of $C$. dubliniensis, there were no significative differences in the number of cells adhering to acrylic in the presence of either fluconazol or amphotericin $\mathrm{B}(1 / 4 \mathrm{MIC}=0.01 \mu \mathrm{g} / \mathrm{ml})$. Observing the morphology under scanning electron microscopy (SEM), after adhesion, it was possible to see that cells incubated with sub-MIC fluconazol formed fewer hyphae than those grown in the presence of sub-MIC amphotericin B, which could explain the differences in adhesion. 
1 Faculdade de Ciências

Farmacêuticas, USP, Brazil

2 Faculdade de Odontologia de Ribeirão Preto, USP, Brazil
* Corresponding author: P. Kiessling

E peggy.kiessling@hki-jena.de

Hans-Knöll-Institut für

Naturstoff-Forschung e.V.

Beutenbergstrasse 11a, D-07745 Jena,

Germany

\section{Inhibition of biofilm formation by mutants group streptococci on toothbrush bristles in vivo}

\author{
I. Y. Ito', M. S. S. Pereira², G. Faria², L. A. B. Silva², \\ E. Watanabe ${ }^{1}$ and P. Nelson-Filho ${ }^{2}$
}

The aim was to evaluate inhibition of biofilm formation through a randomized clinical trial. Using a random number table, 40 children (24-48 months) were divided into 4 groups of 10 individuals. The study consisted of four steps where the following solutions could be used in all the steps by the different groups of children: Periogard, chlorhexidine- $0.12 \%$ (Colgate-Palmolive Kolynos do Brasil Ltd); Brushtox ${ }^{\circledR}$, Antiseptic Toothbrush Cleanser (Dentox Limited, Warwick, UK); Cepacol, cetylpiridinium chloride-0.05\% (Aventis Pharma Ltd, $\mathrm{SP}$ ), and sterilized tapwater (control). Each toothbrush was used only once for $1 \mathrm{~min}$, rinsed, and subjected to a random application of the test solution in spray form. After $4 \mathrm{~h}$ the toothbrushes were placed in $\mathrm{CaSaB}$ broth selective for mutans group streptococci (MGS), and incubated at $37^{\circ} \mathrm{C}$ for $2-3$ days. MGS biofilm developed on all 40 control toothbrushes, but of the others those with Cepacol spray developed biofilm on 25 (62.5\%); with Brushtox ${ }^{\circledR} 9(22.5 \%)$ and with Periogard none. These results were confirmed by scanning electron microscopy. We recommend daily spray sanitization of toothbrushes as part of a routine of infection control.

\section{Quorum sensing of biofilm-associated Erwinia persicinus}

\section{P. Kiessling*, M. Ramm and V. Schroeckh}

Some subterranean locations in southern Europe are of both great prehistoric and archaeological importance and also world-famous tourist venues. Paleolithic paintings in Spanish caves as well as artwork in the early Christian Roman catacombs are in danger of being destroyed by bacterial biofilms growing as a result of illumination and high humidity. Hypogean frescoes are populated by complex microbial communities belonging to highly different taxa. Our aim is to devise convenient techniques for gently reducing the amount of biofilms by targeting bacterial signal transduction pathways.

We isolated a total of 133 heterotrophic bacteria from hypogean artifacts in Italy and Spain and screened them for quorum sensing (QS)-active compounds. Twenty-six strains $(20 \%)$ belonging to 20 different taxa were found to synthesize acylated homoserine lactones (AHLs). One isolate Erwinia persicinus - formed large masses of extracellular polysaccharide (EPS) when grown on agar plates or in liquid culture. Assuming a correlation between AHL-driven QS and EPS formation, we analysed both components. By activityguided fractionation (thin-layer chromatography, high-performance liquid chromatography/mass spectrometry), we demonstrated that E. persicinus forms up to four different AHLs in a time-dependent pattern.

The EPS was shown to contain glucose and galactose and at least one still-unidentified compound. At present we are completing the structural determination of EPS using nuclear magnetic resonance.

The project is funded by the European Union (CATS, EVK4-CT200000028). 


\title{
Growth with sodium dodecyl sulphate induces aggregation and biofilm formation of Pseudomonas aeruginosa strain PAO1
}

\author{
J. Klebensberger, O. Rui, B. Schink \\ and B. Philipp
}

The opportunistic pathogen Pseudomonas aeruginosa strain PAO1 grows with the detergent sodium dodecyl sulphate (SDS) as its sole source of carbon and energy. SDS is toxic to bacterial cells, owing to its interference with membranes and proteins. Growth with, and in the presence of, SDS involved formation of large aggregates and biofilms. In experiments with freely suspended cells, SDS caused a rapid decrease in the optical density, reduction of colony forming units (c.f.u.) and the formation of cell aggregates. Accordingly, filtration of SDS-treated cells through pores of $5 \mu \mathrm{m}$ diameter resulted in a reduction of c.f.u. as compared with non-treated cells. Addition of the protonophore CCCP caused rapid lysis of cells exposed to SDS. Interestingly, KCN and $\mathrm{NaN}_{3}$ prevented the effects of SDS. Both compounds were shown to interfere with respiration and substrate degradation. This suggests that aggregation is an active, energy-requiring response to SDS and that it is not due to purely chemical interaction of the detergent with the cells. Therefore, we propose that this process could play a role in the protection of strain PAO1 against SDS.

* Corresponding author: A. Kolk

E annette.kolk@HVBG.de

\section{Microbial contamination of stationary eyewash units in laboratories}

\section{A. Kolk*, M. Maskus, Y. Otte, G. Schneider and P. Wattrodt}

The institution for statutory accident insurance and prevention in the German chemical industry (BG Chemie) recommends the installation of stationary eyewash units in laboratories because eye injuries caused by corrosion have to be treated quickly by flushing with huge amounts of clean water. Such eyewash units are often not maintained very carefully and biofilms may develop if water stays in there for long periods. There then exists a risk of catching some infectious microorganisms when the units are used in the case of an accident. To estimate this risk and to give advice for the maintenance of such installations, we investigated the microbial contamination of water coming out of two different types of eyewash unit within periods of 1,2 and 4 weeks in the summer of 2003. The results were compared with the microbial quality of normal tapwater, which was used several times daily in the laboratory. Total colony forming units (c.f.u.) of bacteria were determined by incubation at $30{ }^{\circ} \mathrm{C}$ on trypticase-soy-agar; c.f.u. of Pseudomonadae (especially Pseudomonas aeruginosa) were counted on Cetrimid-Agar incubated at $37^{\circ} \mathrm{C}$. We also looked for Acanthamoeba, which are reported in the literature as the causative agent of keratitis. 
* Corresponding author: M. Hoppert

E mhopper@gwdg.de

Institut für Mikrobiologie und Genetik der Universität Göttingen,

Grisebachstrasse 8,

D-37077 Göttingen, Germany
* Corresponding author: J. R. Lawrence

E john.lawrence@ec.gc.ca

1 National Water Research Institute, 11 Innovation Boulevard., Saskatoon, SK, Canada S7N $3 \mathrm{H} 5$

2 Department of Chemistry and Brockhouse Institute for Materials Research, McMaster University, Hamilton, Ontario, Canada L8S 4M1

3 Electron Microscopy Facility, Faculty of Health Sciences, McMaster University, 1200 Main Street West, Hamilton, ON, Canada L8N $3 Z 5$

4 National Water Research Institute, PO Box 5050, 867 Lakeshore Road, Burlington, Ontario, Canada, L7R 4A6

5 Department of River Ecology, UFZ Centre for Environmental Research Leipzig-Halle, Brueckstrasse 3A, 39114 Magdeburg, Germany

\section{Microbial biofilms on building stone}

\section{S. König and M. Hoppert*}

Microbial biofilms are subject to biogenic weathering on natural rocks as well as on building stone. Though the presence of biofilms on stone monuments exposed to the outdoor environment is obvious, thin films also occur on monuments under controllable indoor environmental conditions. Numerous biofilm organisms produce large volumes of extracellular polymers (EP), mainly polysaccharides. Hydrated, gel-like EP act as glue between the organisms and the material surface and provide a protected environment. The contact zone between EP and the material surface is the crucial reactive interface between the bioorganic biofilm and the underlying building stone, since all hazardous compounds (e.g. organic acids) are transferred via EP to the surface. The case studies presented here describe biofilms on the surfaces of stone monuments under indoor and outdoor conditions. The exposed surfaces of these monuments are covered with thin, dark-grey, sometimes crustose layers. The layers consist of mineral precipitates and, partially, of biogenic material - mainly fungal hyphae and extracellular polysaccharides. In order to evaluate the hazardous potential of these films we evaluated the structures of the covers, the role of EP and its interaction with the underlying building stone material.

\section{Scanning transmission X-ray mapping of microbial biofilms and associated metals}

\section{J. R. Lawrence ${ }^{1 *}$, T. Araki ${ }^{2}$, X. Zhang' ${ }^{2}$, M. M. West ${ }^{3}$, G. D. W. Swerhone ${ }^{1}$, G. G. Leppard ${ }^{4}$, T. R. $\mathrm{Neu}^{5}$ and A. P. Hitchcock ${ }^{2}$}

Scanning transmission X-ray microscopy (STXM) is a new tool that may be applied to fully hydrated microbial biofilms. STXM uses the intrinsic $\mathrm{X}$-ray absorption properties of the sample, eliminating the need for the addition of reflective, absorptive, or fluorescent probes. Here we present the results of STXM techniques used to map the distribution of macromolecular subcomponents of a biofilm and associated metals. Results from various edges were combined to map the distribution of nucleic acids, proteins, carbohydrates and lipids in the biofilm community, along with that of $\mathrm{Ni}$ relative to these components. Biopolymers could be detected with a spatial resolution of approximately $50 \mathrm{~nm}$. The exopolymer matrix was clearly dominated by polysaccharides. For $\mathrm{Ni}$, a large degree of metal ion concentration (more than 1000-fold) was observed, along with a very selective distribution. Soft $\mathrm{X}$-ray microscopy provided a combination of suitable spatial resolution and chemical information at the microscale and may be used in combination with other microscopic approaches to create a detailed correlative map of biofilm structure and composition. 
* Corresponding author: C. Leroy

E celine.leroy@ifremer.fr

\section{A marine biofilm formation model in multi-well plates}

\section{Leroy*, C. Compère, C. Delbarre-Ladrat, F. Ghillebaert and D. Combes}

A marine biofilm formation model is needed for the screening of new, non-toxic and efficient antifouling molecules and to better understand the mechanisms of bacterial adhesion. Quantification of bacteria in biofilms is usually performed by microscopy, after labelling of cells or growing cells on agar. These techniques can be tedious and slow and moreover may induce biofilm deterioration by fixing, drying or scraping it. We developed a rapid and sensitive quantitative method. Our model uses a natural biofilm-forming marine bacterium consisting of a monoculture of Pseudoalteromonas on a polystyrene surface in 96-well multi-well plates. DAPI dye (4',6-diamidino-2' phenylindole-dihydrochloride) is then used to stain bacterial DNA and thus to quantify the total biomass of the pseudomarine biofilm developed in each well. Total fluorescence after solubilization of the dye and number of bacteria have been correlated in the test conditions. The marine biofilm growth and the test reproductibility were studied and constituted a rapid and sensitive test.

\section{Secondary metabolites in bacterial biofilms and their protective function against protozoan grazing}

\footnotetext{
School of Biotechnology and Biomolecular Sciences, Centre for Marine Biofouling and Bio-Innovation, University of New South Wales, Sydney 2052, Australia

2 Department of Physiological Ecology, Max Planck Institute for Limnology, D-24302 Plön, Germany

3 School of Chemistry, University of New South Wales, Sydney 2052, Australia

4 Department of Microbiology, Institute of Plant Biology, University of Zürich, $\mathrm{CH}-8008$ Zürich, Switzerland
}

1 Department of Applied Chemistry and Microbiology, University of Helsinki, Finland

2 Department of River Ecology, UFZ Centre for Environmental Research Leipzig-Halle, Magdeburg, Germany

\section{Analysis of Deinococcus geothermalis biofilm properties with lectin staining and confocal laser scanning microscopy}

\section{Peltola ${ }^{1}$, T. R. Neu ${ }^{2}$, U. Kuhlicke ${ }^{2}$ and M. S. Salkinoja-Salonen ${ }^{1}$}

The bacterium Deinococcus geothermalis is known as an important primary biofilm former in many paper machines. It adheres firmly to non-living 
1 Faculdade de Odontologia de Araraquara-UNESP, Araraquara, São Paulo, Brazil

2 NAC-CRD, Araraquara, São Paulo, Brazil

3 Faculdade de Ciências Farmacêuticas-UNESP, Araraquara, São Paulo, Brazil
Universidade Estadual Paulista Julio de Mesquita Filho-Araraquara, SP, Brazil inorganic and organic surfaces such as stainless steel or glass. Lectins are proteins with high carbohydrate specificity and can be used to identify glycoconjugates exposed on cell surfaces or present as lectin-specific extracellular polymeric substances of biofilms. Biofilms of D. geothermalis on a glass surface were probed with 70 different fluorescently labelled lectins and examined using confocal laser scanning microscopy (CLSM). We found 14 lectins that bound to D. geothermalis biofilms. The glycoconjugates were localized on the cell surface, between cells or around microcolonies. Knowledge of the adhesion mechanisms of D. geothermalis can be used to design strategies for biofilm prevention.

Support from the European Committee Marie Curie Fellowship and National Technology Agency's (TEKES) PINTA programme to BIOFOULING project is acknowledged.

\section{Effect of the surface roughness of cast titanium on bacterial colonization}

\section{S. S. Rocha', A. C. A. Bernardi' ${ }^{2}$ A. C. Pizzolitto ${ }^{3}$, G. L. Adabo' ${ }^{1}$ and E. L. Pizzolitto ${ }^{2}$}

Because of its favourable properties, titanium has been used in the manufacture of dentures. The aim of this study was to observe by scanning electron microscopy (SEM) the influence, on Staphylococcus epidermidis colonization, of roughness in the surface of cast titanium. Coupons $(5 \mathrm{~mm} \times 3 \mathrm{~mm})$ were cast in commercially pure titanium (cpTi) and in the Ti-6Al-4V alloy using a Rematitan System. The surfaces of each metal were ground and polished with sandpaper (300-4000) and alumina powder $(0.3 \mu \mathrm{m})$. The surface roughness was measured using Surfcorder SE 1700. For microbiological evaluations, four coupons were inserted separately into Falcon tubes contained Mueller Hinton broth inoculated with $S$. epidermidis $\left(10^{9}\right.$ c.f.u. (colony-forming units)) and incubated at $37{ }^{\circ} \mathrm{C}$. The culture medium was changed every 3 days during a 365 day period, after which the coupons were prepared for SEM, which showed a cocci biofilm. The mean Ra values of CP Ti and of the Ti-6Al-4V alloy were $0.1527 \mu \mathrm{m}$ and $0.1239 \mu \mathrm{m}$, respectively. We conclude that, despite the low degree of roughness, there was bacterial colonization on the cast titanium surface.

\section{Metabolic activity of microbial biofilm on hydroxyapatite-coated titanium surfaces}

\section{A. G. Pires, A. C. Guastaldi, A. C. Pizzolitto and E. L. Pizzolitto}

The aim of this study was to detect quantitatively, using scanning electron microscopy (SEM), Candida albicans and Streptococcus mutans biofilm formation on uncoated commercially pure titanium (cpTi) and hydroxyapatite (HA)-coated surfaces. Coupons of these substances were introduced individually into tubes (Falcon) with Mueller Hinton broth and inoculated, separately, with C. albicans and $S$. mutans suspensions. The tubes were incubated at $37^{\circ} \mathrm{C}$ for $24,48,240$ or $360 \mathrm{~h}$. The cell count of microbes adhering to surfaces was made by SEM magnified 2000 times. On uncoated 
* Corresponding author: M. Ramm E michael.ramm@hki-jena.de

Hans-Knöll-Institut für Naturstoff-Forschung e.V., Beutenbergstrasse $11 \mathrm{a}$, D-07745 Jena, Germany
1 Department of Applied Chemistry and Microbiology, University of Helsinki, Finland

2 Department of Physical Chemistry, Åbo Akademi University, Turku, Finland surfaces, a C. albicans biofilm was observed after a period of $48 \mathrm{~h}$ and the cell counts showed an average of 15 cells. A S. mutans biofilm was visible after 360 $\mathrm{h}$, with an average attachment of 62 cells. On HA-coated surfaces a C. albicans biofilm was observed after $240 \mathrm{~h}$ and the cell counts showed an average of 100 cells. A S. mutans biofilm was observed after $48 \mathrm{~h}$, with an average attachment of 15 cells. Corrosion induced by C. albicans was observed on the cpTi HAcoated surface. We concluded that both surfaces permited C. albicans and $S$. mutans biofilm formation.

\section{Multiple quorum sensing in hypogean biofilms}

\section{Ramm*, P. Kiessling and V. Schroeckh}

Southern Europe is rich in prehistoric and archaeological remains that have enormous cultural and religious importance. Among them are natural and artificial subterreanean locations such as the caves of Altamira and Zuheros in Spain with their famous paleolithic paintings and also the catacombs in Rome, sepulchres of the early Christians. Touristic exploitation of these hypogean monuments requires illumination and causes changes of microclimate, particularly an increase in humidity. These factors promote biofilm formation and subsequent deterioration of the cultural assets by precipitation of minerals and substrate dissolution processes. Biofilms on hypogean frescoes are complex communities of microorganisms belonging to different taxa. In an EU-funded project (CATS) focused on the development of innovative approaches to sustainable management, we investigated the cell-to-cell signalling processes in Gram-negative bacteria isolated from hypogean biofilms. It is known that biofilm growth in some Gram-negative bacteria depends on quorum-sensing (QS) signals. Here we present our results regarding isolation and taxonomical classification of biofilm-associated Gram-negative bacteria. We report the detection of 11 QS-related compounds and the structural identification of five acylated homoserine lactones produced by Cedecea neteri, a scarcely documented human pathogenic bacterium isolated from the Spanish Cave of Bats.

\section{Determination of adsorption isotherms for the attachment of Deinococcus geothermalis by an enzyme-activity-based method}

\section{Raulio', M. Kolari', J. Peltonen², J. B. Rosenholm ${ }^{2}$ and M. S. Salkinoja-Salonen ${ }^{1}$}

Wet industrial processes provide an environment for microbial growth. Adhesion and growth of bacteria on machine surfaces spoil process hygiene and affect machine operation. We studied the adhesion mechanisms of paper-machine bacteria to surfaces. In a paper machine, only a minority of all the microbial taxa present are capable of adhering to a clean surface and initiating the development of multi-species biofilms. We found that Deinococcus geothermalis is one of the most effective primary biofilm formers 
in the paper industry. We investigated the quality and strength of adhesion forces between $D$. geothermalis and a non-living surface. To this purpose we determined adhesion isotherms for the attachment of $D$. geothermalis under different cell concentrations, $\mathrm{pH}$ values and ionic strengths. The quantity of adhering bacteria was measured by a rapid method based on reactivity kinetics of a constitutive bacterial enzyme under substrate-saturated conditions. The suitability of these two methods for biofilm analysis was evaluated.

\section{Biosurfactant from Streptococcus thermophilus A inhibit microbial adhesion on silicone rubber}

\section{Rodrigues, H. C. van der Mei, J. Teixeira and R. Oliveira}

The ability of the biosurfactant obtained from Streptococcus thermophilus A to inhibit adhesion of four bacterial and two yeast strains isolated from explanted voice prostheses to silicone rubber with and without an adsorbed biosurfactant layer was investigated in a parallel-plate flow chamber. The microbial cell surfaces and the silicone rubber, with and without an adsorbed biosurfactant layer, were characterized using contact angle measurements. Water contact angles indicated that the silicone rubber surface with adsorbed biosurfactant was more hydrophilic $\left(58^{\circ}\right)$ than bare silicone rubber $\left(109^{\circ}\right)$. The results obtained showed that the biosurfactant was effective at decreasing the initial deposition rates of Rothia dentocariosa GBJ 52/2B from 1937 to 179 microorganisms $/ \mathrm{cm}^{2}$ pers and of Staphylococcus aureus GB 2/1 from 1255 to 233 microorganisms $/ \mathrm{cm}^{2}$ per s. The deposition rates of Staphylococcus epidermidis GB 9/6, Candida albicans GBJ 13/4A and Candida tropicalis GB 9/9 were reduced in the presence of the biosurfactant to a smaller extent as compared with the other strains. This study constitutes a promising strategy for preventing the microbial colonization of silicone rubber voice prostheses.

1 University of Hanover, Institute of Materials Science, Schönebecker Allee 2, 30823 Garbsen, Germany

2 University of Duisburg-Essen, Institute for Interface Biotechnology, Geibelstrasse 41, 47057 Duisburg, Germany

\section{The influence of nitrogen on the development of biofilms}

\section{J. Scheen ${ }^{1}$, J. Wingender ${ }^{2}$, H. C. Flemming ${ }^{2}$, F. W. Bach' ${ }^{1}$ and P. Wilk'}

Much information has been published about the effects of nutrients on the development of biofilms - but the influence of nitrogen has been neglected. This investigation demonstrates the effects of eight different nitrogen concentrations from a synthetic medium on the development of biofilms. The inoculum was a mixed population from the activated sludge tank of a waste-water treatment plant. A biofilm-reactor arrangement was used to create the biofilms on polyethylene immobilization units. Multiple physical, chemical and biological parameters were monitored to characterize changes in the bacterial biofilm. The results showed the effects of nitrogen availability in synthetic media on the composition of the resulting biofilms and their EPS (extracellular polymeric substances). The content of water, nitrogen, carbohydrate, protein, c.f.u. (colony-forming units) and calcium in biofilms, 
* Corresponding author: B. Scheithauer E brs@gbf.de

1 Division of Microbiology, GBF-German Research Centre for Biotechnology, Mascheroder Weg 1 , 38124 Braunschweig, Germany

2 Surgery Clinic, Braunschweig General Hospital, Klinikum Salzdahlumer Strasse, Salzdahlumer Strasse 90, 38126 Braunschweig, Germany

3 Department of Gastroenterology, University of Ancona, Hospital Torrette, Via Conca, 60100 Ancona, Italy

4 Department of Genetics, University of São Paulo/ESALQ, Av. Pádua Dias 11, 13418-900 Piracicaba SP, Brazil

1 Biochemical Engineering Aachen, RWTH Aachen, 52056 Aachen, Germany

2 Institute for Ceramic Components in Mechanical Engineering, RWTH Aachen, 52056 Aachen, Germany and the EPS, depended on the available nitrogen. The contents of oxygen, hydrogen, carbon and phosphate were not influenced by the available nitrogen. Further investigations have shown that the synthetic medium is suitable for use in corrosion investigations of metallic surfaces (e.g. microbially induced corrosion).

\section{Biogeography of biliary stent community biofilms}

\section{B. Scheithauer ${ }^{1 *}$, B. Ferslev ${ }^{2}$, G. Macarri ${ }^{3}$, F. C. A. Tavares ${ }^{4}$, K. Timmis ${ }^{1}$ and D. F. Wenderoth ${ }^{1}$}

Biliary stents inserted in patients to relieve obstructions of the bile duct are highly likely to become occluded by microbial growth. Previous investigations with occluded stents explanted from various patients in Braunschweig (Germany) and Ancona (Italy) revealed, as members of all investigated stent biofilm communities, the same six abundant populations: Pseudomonas aeruginosa, Klebsiella pneumoniae, Enterococcus faecalis, Enterobacter aerogenes and two unculturable, so-far unidentified species. Currently, samples from different hospitals in different countries are being examined in order to determine the biogeography of abundant and minor species of the biofilm community. Microbial community composition is determined using cultivation-independent methods, i.e. analysis of amplified $16 \mathrm{~S}$ rRNA genes by single-strand conformation polymorphism (SSCP). The fingerprints of the stent communites are compared and single bands representing amplicons of different $16 \mathrm{~S}$ rRNA genes and therefore, ideally, different microorganisms are cut out and sequenced in order to reveal the identites of the corresponding microorganisms. So far the investigations revealed similar major community members in all examined samples.

\section{Development of a novel screening system for the characterization of biofilm growth on different carriers}

\section{J. Seletzky' ${ }^{1}$, K. Otten ${ }^{2}$, H. R. Maier ${ }^{2}$ and J. Büchs ${ }^{1}$}

Prerequisites for a screening system to characterize biofilm growth on different carriers are well-defined environmental conditions over a long period, small carrier size (mass of the carrier $<5 \mathrm{~g}$ ), economic and simple biomass and activity determination and simultaneous operation to investigate several samples in parallel.

Continuous cultivation in shake flasks [1] combines well-defined substrate concentrations with the option to multiply the experimental setup easily. The difficulty is to quantify the extremely small amount of immobilized biomass ( $<20 \mathrm{mg} /$ carrier) because gravimetrical methods are of limited use, particularly when porous carriers are used. Basic optical methods are not applicable when carriers are thick or opaque and the sensitivity of a basic biological test such as the Bradford protein assay (total protein content) is in most cases not high enough. 
To quantify the immobilized biomass the biofilm is completely detached from the carrier with a low concentration of perchloric acid $\left(\mathrm{HClO}_{4}\right)$ and subsequently the optical density of the solution is measured. To determine the aerobic activity of the immobilized microorganisms the oxygen consumption is measured with an oxygen electrode.

\section{REFERENCE}

1. Akgün, A., Maier, B., Preis, D., Roth, B., Klingelhöfer, R. \& Büch, J. (2004) Biotechnology Progress, in press

\section{Prevention of Pseudomonas fluorescens adhesion to surfaces using bacteriophage $\mathbf{S 1}$}

1 University of Minho, Portugal

2 Edinburgh University, Scotland, UK

* Corresponding author: C. Staudt

E staudt@gm.ufz.de

1 Department of River Ecology, UFZ Centre for Environmental Research Leipzig-Halle, Brueckstrasse 3A, 39114 Magdeburg, Germany

2 Hydrochemistry, Hochschule Magdeburg-Stendal (FH), Breitscheidstrasse 2, 39114 Magdeburg, Germany

3 IBVT, Institute for Biochemical Engineering, Technical University of Braunschweig, Gaussstrasse 17, 38106 Braunschweig, Germany

\section{S. Sillankorva ${ }^{1}$, R. Oliveira ${ }^{1}$, M. J. Vieira ${ }^{1}$, I. Sutherland ${ }^{2}$ and J. Azeredo ${ }^{1 *}$}

The presence of biofilms in industrial settings is problematic as bacteria are responsible for several economic losses including product spoilage. Biofilms are difficult to eradicate and, for a long time, their removal and destruction has been attempted using chemical biocides. These agents are relatively ineffective, have negative environmental impacts and the emergence of biocide-resistant bacteria represents a major drawback in their use. Therefore there is increasing interest in the utilization of bacteriophages (phages). Phages are specific for a bacterial host or a range of hosts, active against biocide-resistant bacteria and considered to be environmentally innocuous. This work focuses on the use of bacteriophage S1 to prevent Pseudomonas fluorescens biofilm formation. Glass and stainless steel surfaces were coated with suspensions of $10^{9}$ plaque-forming units (p.f.u.)/ml prior to bacterial adhesion tests. The results obtained showed that $P$. fluorescens was no longer able to adhere to these surfaces. Moreover, after several washings of the surface the remaining attached phages (about $10^{3}$ p.f.u./ml) were still able to prevent biofilm formation on the surfaces.

\section{ConAn, a new software developed for digital image analysis of three-dimensional biofilm data}

\author{
C. Staudt ${ }^{1,2 *}$, H. Horn ${ }^{2}$, D. C. Hempel ${ }^{3}$ and T. R. Neu ${ }^{1}$ \\ Confocal laser scanning microscopy (CLSM) has developed into an \\ indispensable technique for biofilm structural studies. However, digital image \\ analysis of three-dimensional data sets still represents a big challenge. The \\ programs available include freely available software as well as commercial \\ software. None of the programs is suitable for multi-purpose applications \\ in environmental microbiology. Therefore the new software Confocal \\ Analysis (ConAn) was developed which allows the analysis of complex \\ three-dimensional data sets. The analysis of ConAn includes visualization, \\ quantification and calculation of structural parameters. Furthermore, the
}


* Corresponding author: C. Staudt

E staudt@gm.ufz.de

1 Department of River Ecology, UFZ Centre for Environmental Research Leipzig-Halle, Brueckstrasse 3A, 39114 Magdeburg, Germany

2 Hydrochemistry, Hochschule Magdeburg-Stendal (FH), Breitscheidstrasse 2, 39114 Magdeburg, Germany

3 IBVT, Institute for Biochemical Engineering, Technical University of Braunschweig, Gaussstrasse 17, 38106 Braunschweig, Germany
* Corresponding author: E. Storgårds E erna.storgards@vtt.fi

1 VTT Biotechnology, P.O. Box 1500, FIN-02044 VTT, Finland

2 TFH Berlin, Luxemburger Strasse 10, D-133353 Berlin, Germany program can handle multi-channel data, co-localized data and staple analysis of multiple files. In this study the software was used to analyse biofilms grown in rotating annular reactors under different substrate and shear conditions. Distribution of cell biomass and glycoconjugate biomass was determined across biofilm depth and followed over a period of up to 100 days. In addition, different structural parameters such as mean/maximal thickness, roughness, mean/maximum diffusion distance, and porosity were analysed. By employing ConAn, digital image analysis was simplified and improved with respect to routine analysis of multiple files.

\section{Lectin-binding-analysis of rotating annular reactor cultivated biofilms}

\section{Staudt ${ }^{1,2 *}$, H. Horn ${ }^{2}$, D. C. Hempel ${ }^{3}$ and T. R. Neu ${ }^{1}$}

Bacterial cells and extracellular polymeric substances (EPS) have been identified as major components of interfacial microbial communities. After fluorescent staining of these two biofilm constituents and subsequent confocal laser scanning microscopy the structure and function of biofilm systems can be studied. Bacteria (cell biomass) may be stained with standard nucleic acid stains whereas EPS glycoconjugates (glycoconjugate biomass) may be stained using fluor-conjugated lectins. In this study, river and waste-water biofilms were grown in rotating annular reactors and examined by employing all of the 63 commercially available lectins. From the lectins tested, about 40 showed a useful binding pattern. Nevertheless, the various lectins had a different staining pattern if chemoautotrophic and heterotrophic biofilms were compared. As a consequence of lectin specificity and biofilm characteristics, a panel of appropriate lectins must be determined for each type of biofilm system. After selecting a panel of suitable lectins they may be employed in order to stain glycoconjugates (1) directly on the cell surface, (2) associated with microcolonies or (3) in the cell-free EPS matrix.

\section{Adhesiveness and hydrophobicity of food spoilage yeasts}

\section{E. Storgårds ${ }^{1 *}$, F. Schreiber ${ }^{2}$ and R. Juvonen ${ }^{1}$}

Yeasts are spoilage organisms in many food-processing industries, where they may grow as biofilms on the surfaces of process equipment. Relevant information about the adhesion characteristics of food spoilage yeasts is needed to be able to efficiently prevent the early stages of biofilm formation by control of process parameters. Hydrophobicity has been found to affect attachment of microbial cells to solid surfaces. In this study, the adhesiveness and hydrophobicity of yeast cells isolated from food production processes was investigated. A trend between strong hydrophobicity and high adhesion rate could be observed. The most hydrophobic yeast strains belonged to the species Candida intermedia, Rhodotorula mucilaginosa and Zygosaccharomyces rouxii; the most adhesive strains also belonged to these species, with the addition of Trichosporon asahii. However, a clear correlation between adhesion and 
hydrophobicity could not be shown. Probably other cell surface properties in addition to hydrophobicity also affect the adhesion rate of yeast cells to surfaces.

1 Hydrochemistry, Hochschule Magdeburg-Stendal (FH), 39114 Magdeburg, Germany

2 Institute for Micro- and Sensor Systems (IMOS), O.-v-G.-Universität Magdeburg, Germany
* Corresponding author: J. G. Fonseca

E jfonseca@alf1.cii.fc.ul.pt

1 CEB, University of Minho, 4710-057 Braga, Portugal

2 Department C. Mater. \& CENIMAT, FCT - UNL, Quinta da Torre, 2825 Monte da Caparica, Portugal

3 CFMC - UL, Av. Prof. Gama Pinto 2, 1649-003 Lisboa, Portugal

\section{Investigation of microbial adhesion on a thickness shear mode resonator}

\section{Teichmann', H. Horn', J. Hartmann', R. Lucklum² and P. Hauptmann ${ }^{2}$}

A thickness shear mode resonator (TSM) has been used for inline and online monitoring of microbial adhesion and biofilm growth. For this, autotrophic and heterotrophic mixed-culture biofilms were cultivated under defined hydrodynamic conditions in a tube reactor. The signal of the sensor was induced by the adhesion of microorganisms to the gold electrode of the quartz disc, which was vibrating with a fundamental frequency of $10 \mathrm{MHz}$. The frequency change can be used as a signal for the early detection of unwanted biofilm growth owing to mass accumulation on the sensor's surface. Simultaneously we recorded the change of the acoustic impedance so as to access biofilm properties such as viscosity. Both signals can be displayed online and in real time via a personal computer. Measurements of biofilm thickness and of changes in biofilm structure have been carried out on coupons outside the tube reactor, with a confocal laser scanning microscope at different stages of biofilm growth as an independent second method.

\section{Staphylococcus epidermis adhesion on modified urea/urethane elastomers}

\section{P. Teixeira ${ }^{1}$, A. C. Trindade ${ }^{2}$, J. G. Fonseca ${ }^{3 *}$, J. Azeredo', R. Oliveira ${ }^{1}$ and M. H. Godinho ${ }^{2}$}

Block urea/urethane co-polymer films present elastomeric properties with the possible tuning of their surface properties within a wide range and are therefore considered appropriate surfaces for microbial adhesion studies. In particular, urea/urethane elastomers develop multi-stable states with surface topography features that have remarkable regularity. Moreover, complex surface structures may be obtained by suitable mechanical action or ultraviolet radiation treatment and also by extraction of the elastomer with a selected solvent. In the present work, different surfaces were assayed for Staphylococcus epidermidis adhesion over $2 \mathrm{~h}$ and the extent of bacterial adhesion was evaluated by automated cell enumeration. A general trend was observed, relating increase in the number of cells adhering to increase in the surface roughness. The detailed relation between the surface properties of the modified elastomers (namely their surface topography characteristics and surface tension) and the S. epidermidis surface adhesion density is reported and discussed. 
1 Institut für Molekulare Enzymtechnologie, Heinrich-Heine-Universität Düsseldorf, D-40225 Düsseldorf, Germany

2 Institut für Aquatische Mikrobiologie, Gerhard-Mercator-Universität Essen-Duisburg, D-47048 Duisburg, Germany

3 Institut voor Moleculaire Biologie, Vrije Universiteit Brussel, B-1050 Brussel, Belgium

\section{Pseudomonas aeruginosa lectin LecB is a cell surface protein involved in biofilm formation}

\author{
D. Tielker ${ }^{1}$, S. Hacker ${ }^{1}$, F. Rosenau', \\ M. Strathmann ${ }^{2}$, J. Wingender ${ }^{2}$, R. Loris ${ }^{3}$ \\ and K.-E. Jaeger ${ }^{1}$
}

Treatment of Pseudomonas aeruginosa infections is still difficult because the bacteria exhibit a high intrinsic resistance to a variety of different antibiotics and form stable biofilms. The bacterium produces the two cytotoxic lectins, LecA and LecB, that facilitate bacterial adhesion to the airway mucosa [1]. The crystal structure of LecB was recently determined [2,3]. We have studied the physiology of the (L)-fucose-specific lectin LecB. The lecB gene was cloned and overexpressed and the $\mathrm{LecB}$ protein purified and used to produce a LecB-specific polyclonal antiserum. A LecB-deficient $P$. aeruginosa mutant was unable to colonize glass slides. This result suggested an important role for LecB in the process of biofilm formation, prompting us to investigate the cellular distribution of this lectin by fractionation of biofilm cells and subsequent sucrose density gradient centrifugation followed by immunoblotting. In addition, we fractionated cells synthesizing a LecB variant carrying a defective sugar-binding site. Our results showed clearly that LecB is abundantly present in the bacterial outer membrane fraction. Additionally, we showed that LecB can be specifically released by treatment of the outer membrane fraction with (L)-fucose, indicating that LecB is bound to fucose-containing polysaccharide ligands located on the bacterial cell surface.
Abteilung Mikrobiologie, Fachbereich Biologie/Chemie, Universität Osnabrück, 49069 Osnabrück, Germany

\section{Aerobic biofilms as Trojan horses for anaerobic product spoiling bacteria?}

\section{Timke, N. Q. Wang-Lieu, K. Altendorf and $A$. Lipski}

The initial colonization of surfaces is carried out by aerobic microorganisms. Anaerobic microenvironments may be formed in mature biofilms as a result of oxygen-consuming metabolism. These anaerobic niches represent a habitat for beer-spoiling bacteria such as Lactobacillaceae and the strictly anaerobic genera Megasphaera and Pectinatus. To assess the biological relevance of anaerobic niches, the mature biofilms were investigated using two $16 \mathrm{~S}$ rDNA clone libraries for the presence of obligately anaerobic bacteria. In total, 217 and 80 clones were analysed by amplified $16 \mathrm{~S}$ rDNA gene restriction 
* Corresponding author: D. Tyszler

Edty@ivt.rwth-aachen.de

1 University of Guelph, School of Engineering, Guelph, ON, Canada N1G 2W1

2 RWTH Aachen, Department of Chemical Engineering, Turmstrasse 46, D-52056 Aachen, Germany analysis (ARDRA), respectively. There were 53 and 59 different patterns in the clone libraries, of which 29 and 48 were unique. The main groups identified by sequencing belonged to Gamma- and Alphaproteobacteria and Flavobacteria/Sphingobacteria. None of the sequences could be assigned to obligate anaerobic bacteria. Quantitative data about the detected groups were obtained by fluorescent in situ hybridization and analysis of the fatty acid profile. Despite intense disinfecting and cleaning procedures, the clone libraries revealed a high diversity, which was restricted to only aerobic bacteria.

\section{Reduced fouling tendencies of ultrafiltration membranes in waste-water treatment by plasma modification}

\section{Tyszler ${ }^{1,2 *}$, A. Brügger ${ }^{2}$, S. Geissler ${ }^{2}$, R. Zytner ${ }^{1}$, H. Zhou ${ }^{1}$ and T. Melin ${ }^{2}$}

Membrane technology has become one of the key technologies in the future of waste-water treatment. Since the efficiency and performance of this technology is strongly hindered by fouling, future developments in membrane filters strive to reduce this phenomenon. Previous studies have shown that plasma-modified membranes revealed promising results in fouling reduction $[1,2]$. As part of a collaborative project with the University of Guelph, Ontario, Canada, the Department of Chemical Engineering (IVT), RWTH Aachen, the PURON AG, and the German Wool Research Institute, RWTH Aachen, the work presented focused on the modification of polyethersulfone (PES) membranes for wastewater treatment plant applications, to achieve an increase in effluent flux and fouling resistance. With the aid of an environmentally friendly plasma technology, the hydrophilic characteristics of the membrane's surface are improved. This leads to a reduction in the membrane's adsorption affinity for foulants such as EPS, while increasing the membrane's permeate flux.

The project scope includes:

(a) Comparison of modified and unmodified membranes' physical properties (molecular weight cut-off, bubble point, contact angle, permeability, etc.)

(b) Chemical and physical endurance tests of the modified and unmodified membranes

(c) "Single-strand" test cell fouling studies to determine the most promising plasma treatment method

(d) On-site pilot plant studies at the local waste-water treatment plant to compare the original PES membranes and their modified counterparts. Initial analysis of the unmodified and modified membranes under laboratory conditions has been performed, and new equipment and methods were employed to aid in the characterization of the membranes' filtration capabilities and separation boundaries. On the basis of the results obtained, membranes modified with the most promising methods ( $\mathrm{O}_{2}$-Plasma, Ar-Plasma, Corona Treatment, PAAc Graft polymerization and HEMA polymerization) were selected for further analysis. A fully automated "single-strand" test cell is employed to determine the most fouling-resistant plasma modification method. Furthermore, long-term fouling tendencies, investigated under real operating conditions, are studied with the aid of a pilot plant located at the waste-water treatment plant in Aachen Eilendorf. The poster presentation offers an overview of the promising modification methods and their impact on fouling reduction of UF-membranes employed in waste-water treatment. 


\section{REFERENCES}

1. Kim, K. S., Lee, K. H., Cho, K. \& Park, C. E. (2002) Journal of Membrane Science 199, 135-145

2. Wavhal, D. S. \& Fisher, E. R. (2002) Journal of Membrane Science 209, 255-269
* Corresponding author: A. A. Gorbushina

1 Geomicrobiology, ICBM, Carl von Ossietzky University Oldenburg, P.O. Box 2503, D-26111 Oldenburg, Germany
* Corresponding author: C. Von Ohle

1 Dental Clinic, University of Tübingen, Germany

2 Institute of Anatomy, University of Tübingen, Germany

\section{A universal method for analysing the diversity of mycosporines and mycosporine-like amino acids in microorganisms and environmental rock inhabiting microbial communities}

\author{
M. Volkmann, W. E. Krumbein, K. A. Palinska, \\ and A. A. Gorbushina*
}

Mycosporines and mycosporine-like amino acids (MAA) are frequent protective substances in prokaryotic and eukaryotic microorganisms. The major function of these low molecular mass ultraviolet (UV) B absorbing hydrophilic compounds is their capacity to act as photoprotective UV filters (in prokaryotes) or to exercise a regulatory effect on sporulation (in eukaryotes). Furthermore they can serve as antioxidants and/or have osmoprotective function. Pure cultures of diverse microorganisms have been studied. The organisms under investigation were eukaryotic fungi (ascomycetes, basidiomycetes, deuteromycetes) and prokaryotes (actinomycetes of the Geodermatophilus genus and different cyanobacteria) that were screened for their content and diversity of mycosporines and MAAs. Furthermore, natural stone samples such as marble and various sandstones were extracted and the UV-B-absorbing compounds were characterized. After sensitive extraction of the water-soluble contents, reversed-phase high-performance liquid chromatography (HPLC) coupled with mass spectrometry was used to quantify and identify the UV-B-absorbing compounds. In total, five MAAs, eight mycosporines and one UV-absorbing substance that is as yet unknown were successfully extracted and separated by this method. It is likely that chemically highly unstable mycosporines and MAA on the rock surface are protected either by the presence of living cells or by physical and chemical interactions with the rock substrate itself.

\section{In vivo biofilm formation on dental hard tissues}

\section{Von Ohle ${ }^{1 *}$, E. M. Decker ${ }^{1}$, A. Mack ${ }^{2}$ and M. Brecx ${ }^{1}$}

The aim of this study was to non-destructively visualize the structure and vitality pattern of intact supragingival dental biofilms on exposed enamel and dentine surfaces after different periods of biofilm formation $(4,8,24,48$, $72 \mathrm{~h}$ ) using confocal laser scanning microscopy (CLSM). Standardized human enamel and dentine pieces (surface roughness $0.33 \pm 0.09 \mu \mathrm{m}$ ) were used for the in vivo collection (six healthy volunteers) of undisturbed biofilms. After staining (SYTO 9/ PI) the biofilms were analysed by CLSM. Biofilm thickness (BT), area of colonization $(C)$ and the percentage of vital microorganisms $(V)$ in representative layers as well as total bacterial counts $\left(\mathrm{BC} / \mathrm{mm}^{2}\right.$, darkfield 
microscopy) were investigated. For statistical analysis the mean based 95\% confidence intervals were calculated for each parameter. With increasing age, biofilms grew exponentially and the structure became very complex, but because of large interindividual variations no general vitality pattern could be observed inside. Comparing biofilms grown on the dissimilar dental hard tissues, enamel and dentine, no significant differences with respect to BT, $C, V$ and $\mathrm{BC}$ were detected.

1 Klinik für Unfall- und Wiederherstellungschirurgie, Berufsgenossenschaftliche Unfallklinik Ludwigshafen, Germany

2 Institut für Immunologie, Universität Heidelberg, Germany
* Corresponding author: T. R. Neu

E neu@gm.ufz.de

1 Department of River Ecology, UFZ Centre for Environmental Research Leipzig-Halle, Brueckstrasse 3A, 39114 Magdeburg, Germany

2 Biotechnology/Microbiology, Hochschule Magdeburg-Stendal (FH), Breitscheidstrasse 2, 39114 Magdeburg, Germany

\section{Implant-associated osteomyelitis: analysis of the local cellular immune response}

\section{Wagner ${ }^{1}$, T. Bernschneider ${ }^{1}$, V. Heppert ${ }^{1}$, A. Wentzensen ${ }^{1}$ and $G$. M. Hänsch ${ }^{2}$}

Formation of bacterial biofilms on endoprotheses or implants used for osteosynthesis are supposed to be the major cause of the development of osteomyelitis. To analyse the role of immunocompetent cells, the infected site was rinsed while removing the implant. An average of between $1 \times 10^{7}$ and $2 \times 10^{7}$ leukocytes ( $n=20$ patients) were recovered, consisting of polymorphonuclear neutrophils (PMN) (75-90\%); T-lymphocytes (5-10\%) and monocytes and B-lymphocytes $(<5 \%)$. The PMN were highly activated, as seen by an upregulation of the high affinity receptor for IgG, CD64, of the LPS-receptor and CD14, as well as by a downregulation of L-selectin (CD62L). Moreover, elastase surface expression was seen, as was priming for superoxide generation. All these modulations were seen for PMN derived from the lavage, but not, or to a lesser degree, for the cells of the peripheral blood, indicative of a local activation. In conclusion, PMN infiltrate the infected site, but despite local activation they are unable to clear the bacteria, possibly because of biofilm formation.

\section{Fluorescence lifetime imaging (FLIM) of interfacial microbial communities}

\section{P. Walczysko', U. Kuhlicke', S. Knappe ${ }^{2}$, C. Cordes $^{2}$ and T. R. Neu ${ }^{1 *}$}

In comparison to fluorescence intensity imaging, for example confocal laser scanning microscopy (CLSM), fluorescence lifetime imaging (FLIM) allows the recording of additional information from the microenvironment of the fluorochrome. We used the fluorescence lifetime of a nucleic acid-specific probe directly as a measure of the RNA/DNA ratio inside living bacterial cells. In vitro, the nucleic acid dye SYTO 13 showed lower fluorescence lifetimes in DNA solutions as compared with RNA solutions. Growth experiments with bacterial monocultures demonstrated the suitability of SYTO 13 to measure the growth phase-dependent RNA/DNA ratio in Escherichia coli cells. Finally, the fluorescence lifetime of SYTO 13 in slow and fast growing biofilms was compared. For this purpose biofilms were grown as autotrophic and heterotrophic communities on pumice in an airlift loop reactor. The FLIM data clearly showed a higher fluorescence lifetime for the fast-growing heterotrophic 
ECHEM Center for Applied Electrochemistry, Wiener Neustadt, Austria biofilms and a lower fluorescence lifetime for the slow-growing autotrophic biofilms. It is suggested that FLIM in combination with SYTO 13 represents a powerful tool for in situ differentiation of fast- and slow-growing bacteria in environmental biofilm communities.

\section{Concepts of electrochemical treatment and useful techniques for proper implementation}

\section{W. Wesner}

Using electric current provides a variety of effects which may be able to reduce biofilm accumulation. Many parameters change with the electric field: the migration of charged molecules and particles leads to a local change in $\mathrm{pH}$; the production of oxygen at the anode accelerates the biological turnover; and the generation of disinfectants such as chlorine, ozone, superoxide, hydrogen peroxide and free radicals at the anode has the ability to destroy bacteria, if their concentration exceeds certain levels. The biofilm is affected by the electric field in a reversible change of thickness, using alternating or pulsed current that leads to an increased susceptibility. In combination with antibiotics or even simple disinfectants, the "bioelectric effect" has been described. Disinfectants that are not able to migrate into the biofilm, commonly said to be ineffective, can show discernable activity when applied in combination with current. In terms of implementation techniques, special attention should be paid to the electrode material. One concept is to use self-dissolving anodes, liberating silver or copper ions as preservation agents. A newly developed technique employs dimension-stable anode materials, showing a high overpotential with respect to the evolution of oxygen. Boron-doped diamond is the inert material that sets new standards in electrochemical treatment. In combination with titanium surfaces, for pipes, medical instruments, wet metal surfaces, etc., doped diamond produces excellent disinfectants directly in the biofilm. Even complete degradation of an organic substance to $\mathrm{CO}_{2}$ is possible.

\section{Inhibition of Staphylococcus aureus biofilm formation on vascular graft surfaces coated with elemental silver}

\section{Strathmann and J. Wingender}

The antimicrobial silver coating of medical prostheses is regarded as a means of reducing the risk of bacterial colonization after implantation. The effect of elemental silver-modified vascular graft surfaces on biofilm formation was assessed in batch cultures of Staphylococcus aureus by microscopic techniques. Using confocal laser scanning microscopy, total cells in biofilms were analysed by staining with the DNA-binding fluorochrome SYTO 62 and the proportion of damaged cells was quantified with the membrane potentialsensitive dye bis-(1,3-dibutylbarbituric acid)trimethine oxonol. Both the extent of biofilm formation and the proportion of viable biofilm cells were significantly diminished on the surface of the silver-coated vascular grafts as compared with uncoated controls. Analysis by scanning electron microscopy confirmed the formation of reduced biofilm amounts on silver-coated grafts, and demonstrated that extracellular material surrounding bacterial cells on 
Universität Tübingen, Mikrobielle Genetik, Auf der Morgenstelle 28, Germany
* Corresponding author: R. Witzig

E rwi@gbf.de

German Research Centre for Biotechnology, Department of Environmental Microbiology, Mascheroder Weg 1, 38124

Braunschweig, Germany uncoated grafts was not visible around cells on silver-coated surfaces. These observations suggest that the inhibitory effects on biofilm formation were probably due to the antimicrobial activity of silver released from the modified graft surfaces.

\section{A. Resch and F. Götz}

Biofilm formation by staphylococci on implanted medical devices is a serious health problem and leads to chronic polymer-associated infections. Bacteria in these biofilms cannot be conventionally treated with antibiotics and often the only cure is removal of the device. To find new, effective ways of treatment it is important to gain a deeper understanding of biofilm formation, to examine the expression patterns of staphylococci in biofilms and to find new virulence genes involved in biofilm formation. For the required broad screening of expression patterns under differential growth conditions, DNA microarrays were used. Thus an in vitro biofilm model for Staphylococcus aureus on agar plates was established and bacteria were harvested at different times for the isolation of mRNA. The references for the microarrays were planktonically grown S. aureus cells. With bioinformatic analysis of the microarray data it was determined that several genes are up- or downregulated in a biofilm. With databank homology searches and comparison with $S$. aureus microarrays for other growth conditions, it could be confirmed that some of these genes are involved in the virulence and persistence of $S$. aureus biofilms. Further evidence will be gained by examination of the proteome with two-dimensional gel electrophoresis and by conducting in vitro/ in vivo tests with knockout mutants.

\section{Diversity of the microbial community and the catabolic genes in biofilms grown on polychlorinated biphenyls droplets}

\section{R. Witzig*, H. Lünsdorf, W.-R. Abraham, K. N. Timmis and D. F. Wenderoth}

Microbial communities play an important role in the removal of persistent environmental pollutants such as polychlorinated biphenyls (PCBs). Since in situ removal rates of PCBs are generally exceptionally slow, the challenge is to find ways of realizing the full potential of PCB degraders. A first step will be the identification of microbes participating in the degradation of the target pollutant and the identification of the genes involved in PCB metabolism. As with most natural bacterial populations, soil consortia are attached to surfaces where they grow as highly structured communities in biofilms. In our study, we reproduced functional biofilm communites from PCB-contaminated soil on PCB droplets. Analysis of the $16 \mathrm{~S}$ rDNA sequence diversity in biofilm consortia was conducted using polymerase chain reaction (PCR) 


\footnotetext{
* Corresponding author: M. Wulkow

Em.wulkow@cit-wulkow.de

1 Computing in Technology GMBH, Rastede, Germany

2 Hochschule Magdeburg-Stendal (fh) Hydrochemistry, Germany
}

and single-strand conformation polymorphism (SSCP). To investigate the diversity of PCB-catabolic genes, a new SSCP approach using PCR-amplified gene fragments of aromatic ring-hydroxylating dioxygenases (ARHDOs) was developed. Fingerprints of $16 \mathrm{~S}$ rDNA showed no significant shift in the community composition of biofilms grown on PCB droplets for 16, 28 and 42 days in the soil microcosm. Members of the biofilm consortium were related mainly to the genus Burkholderia. However, repeated growth experiments in the same microcosm revealed some variation in the community composition, although several community members were present in all biofilms sampled. In contrast to the considerable variability and high complexity of the community structure, only two different ARHDOs could be detected by the use of the newly developed ARHDO-SSCP in all biofilms. The inferred peptide sequences from the two gene fragments were homologous to the biphenyl dioxygenases of Burkholderia fungorum LB400 and Pseudomonas sp. Cam-1, respectively. Pure culture strains of the genus Burkholderia that had previosly been isolated from PCB biofilms and were closely related to the Burkholderia strains found in the community fingerprints were used for screening of ARHDO sequences. ARHDO-SSCP fingerprints from positively tested isolates and subsequent sequencing of the SSCP bands revealed that phylogenetically distinctive Burkholderia strains possessed the same biphenyl dioxygenase gene. Comparison of the fingerprint pattern and retrieved ARHDO sequences also revealed that the ARHDO fragment shared by the Burkholderia strains was identical with the Cam-1-like biphenyl dioxygenase found in the biofilms.

\section{A modular approach to the mathematical modelling of biofilm systems}

\section{Wulkow ${ }^{1 *}$ and H. Horn ${ }^{2}$}

Mathematical models of chemical or biological processes not only provide greater insight into microscopic mechanisms but also describe and predict the behavior of such systems in a quantitative way. In the field of biofilm modelling, such models can be used for the description of growth, detachment, composition of biofilm and much more. A most attractive feature of these models is the possibility of "re-use" in very different modelling environments. The model basis presented has been developed and validated over years and could be applied successfully to: (a) dynamic models, with a full description of the biofilm with internal coordinates and a second axis for the position along a bioreactor; and (b) plug-flow models, with a full description of convection and diffusion in biofilm in tube reactors or small rivers.

We present the modularity of the approach, give a brief overview of the mathematical techniques used and present new simulation results, in particular the distribution of extracellular polymeric substances in the biofilm and the detachment of biomass from the biofilm surface.

\section{The study of castor-oil-derived polyurethane in relation to biofilm}

\section{S. Yokoo', A. C. Pizzolitto', O. G. Chierice ${ }^{2}$ and E. L. Pizzolitto'}

Microbial biofilms are having a strong economic impact on public health. The aim of this research was to observe, by scanning electron microscopy 
(SEM), Staphylococcus epidermidis biofilm formation on polyurethane, as well as to determine the hydrophobic index of the cellular surface of this selected organism. The coupons $(1.0 \mathrm{~cm} \times 1.0 \mathrm{~cm})$ of castor-oil-derived polyurethane were inserted, one by one, into separate tubes (Falcon) containing Mueller Hinton broth, inoculated with $0.2 \mathrm{ml}$ of the microbial suspension $\left(10^{9} \mathrm{cells} / \mathrm{ml}\right)$ and incubated at $37^{\circ} \mathrm{C}(100$ r.p.m. (revolutions per minute) $)$ for $30 \mathrm{~min}$ and 2, 4, 6, 24, $48 \mathrm{~h}$ periods. The hydrophobic index was determined using the method of bacterial adherence to hydrocarbons and, as a result, S. epidermidis was classified as hydrophobic. The SEM observations showed cocci attachment and biofilm formation on the castor-oil-derived polyurethane surfaces at the different intervals of incubation. We thus concluded that castoroil-derived polyurethane surfaces do not inhibit S. epidermidis ATCC12228 RP62A attachment and biofilm formation.

* Corresponding author: W. R. Streit

1 Institut für Mikrobiologie und Genetik, Universität Göttingen,

Grisebachstrasse 8, 37077

Göttingen, Germany

2 Laboratorium für Genomanalyse, Universität Göttingen,

Grisebachstrasse 8, 37077

Göttingen, Germany

3 Institut für Grenzflächenbiotechnologie, Universität Duisburg-Essen, Geibelstrasse 41, 47057 Duisburg, Germany

4 Institut für Molekulare Enzymtechnologie, Heinrich Heine-Universität Düsseldorf, Forschungszentrum Jülich, 52425 Jülich, Germany

5 Gesellschaft für Biotechnologische Forschung (German Research Centre for Biotechnology), Mascheroder Weg 1, 38124 Braunschweig, Germany

\section{Metagenome survey of biofilms in drinking water networks}

\section{Schmeisser ${ }^{1}$, C. Stöckigt ${ }^{1}$, J. Wingender ${ }^{3}$, K. N. Timmis ${ }^{5}$, D. F. Wenderoth ${ }^{5}$, H.-C. Flemming ${ }^{3}$, H. Liesegang ${ }^{2}$, R. A. Schmitz ${ }^{1}$, K.-E. Jaeger ${ }^{4}$ and W. R. Streit ${ }^{1 *}$}

Most naturally occurring biofilms contain a vast majority of microorganisms that have not yet been cultured and therefore we have only scant information on the genetic information content of these communities. So, by employing three different strategies, we have initiated work to characterize the complex metagenome of model drinking-water biofilms grown on rubber-coated valves. First, a sequence analysis of $65016 \mathrm{~S}$ rRNA clones indicated a high diversity within the biofilm communities, with the majority of the microbes being closely related to the Proteobacteria. Only a small fraction of the $16 \mathrm{~S}$ rRNA sequences was highly similar to rRNA sequences from Actinobacteria, low G+C Grampositives and the Cytophaga-Flavobacterium-Bacteroides (CFB) group. Our second strategy included a snapshot genome sequencing approach. Homology searches in public databases with 5000 random sequence clones from a small insert library resulted in the identification of 2200 putative protein-coding sequences, of which 1026 could be classified into functional groups. Similarity analyses indicated that significant fractions of the genes and proteins identified were highly similar to known proteins observed in the genera Rhizobium, Pseudomonas and Escherichia. Finally, we report $144 \mathrm{~kb}$ of DNA sequence information from four selected cosmid clones, of which two formed a $75 \mathrm{~kb}$ overlapping contig. The majority of the proteins identified by whole cosmid sequencing probably originated from microbes closely related to the Alpha-, Beta-, and Gammaproteobacteria. The sequence information was used to set up a data base containing the phylogenetic and genomic information on this model microbial community. Concerning a potential health risk of the studied microbial community, no DNA or protein sequences directly linked to pathogenic traits were identified. 